\title{
High-Density Lipoprotein Cholesterol and Cardiovascular Events in Patients with Stable Coronary Artery Disease Treated with Statins: An Observation from the REAL-CAD Study
}

\author{
Kazunori Omote ${ }^{1}$, Isao Yokota ${ }^{2}$, Toshiyuki Nagai ${ }^{1}$, Ichiro Sakuma ${ }^{3}$, Yoshihisa Nakagawa ${ }^{4}$, \\ Kiwamu Kamiya ${ }^{1}$, Hiroshi Iwata ${ }^{5}$, Katsumi Miyauchi ${ }^{5}$, Yukio Ozaki ${ }^{6}$, Kiyoshi Hibi ${ }^{7}$, Takafumi Hiro ${ }^{8}$, \\ Yoshihiro Fukumoto ${ }^{9}$, Hiroyoshi Mori ${ }^{10}$, Seiji Hokimoto ${ }^{11}$, Yasuo Ohashi ${ }^{12}$, Hiroshi Ohtsu ${ }^{13}$, Hisao Ogawa ${ }^{14}$, \\ Hiroyuki Daida ${ }^{5}$, Satoshi limuro ${ }^{15}$, Hiroaki Shimokawa ${ }^{16}$, Yasushi Saito ${ }^{17}$, Takeshi Kimura ${ }^{18}$, \\ Masunori Matsuzaki ${ }^{19}$, Ryozo Nagai ${ }^{20}$ and Toshihisa Anzai ${ }^{1}$ on behalf of the REAL-CAD study investigators \\ ${ }^{1}$ Department of Cardiovascular Medicine, Faculty of Medicine and Graduate School of Medicine, Hokkaido University, Sapporo, Japan \\ ${ }^{2}$ Department of Biostatistics, Graduate School of Medicine, Hokkaido University, Sapporo, Japan \\ ${ }^{3}$ Caress Sapporo Hokko Memorial Clinic, Sapporo, Japan \\ ${ }^{4}$ Department of Cardiovascular Medicine, Shiga University of Medical Science Hospital, Shiga, Japan. \\ ${ }^{5}$ Department of Cardiovascular Medicine, Juntendo University Graduate School of Medicine, Tokyo, Japan \\ ${ }^{6}$ Department of Cardiology, Fujita Health University School of Medicine, Aichi, Japan \\ ${ }^{7}$ Division of Cardiology, Yokohama City University Medical Center, Yokohama, Japan \\ ${ }^{8}$ Division of Cardiology, Department of Medicine, Nihon University School of Medicine, Tokyo, Japan \\ ${ }^{9}$ Division of Cardiovascular Medicine, Department of Internal Medicine, Kurume University School of Medicine, Fukuoka, Japan \\ ${ }^{10}$ Department of Cardiology, Showa University Fujigaoka Hospital, Yokohama, Japan \\ ${ }^{11}$ Department of Cardiovascular Medicine, Kumamoto University Hospital, Kumamoto, Japan \\ ${ }^{12}$ Department of Integrated Science and Technology for Sustainable Society, Chuo University, Tokyo, Japan \\ ${ }^{13}$ National Center for Global Health and Medicine, Center for Clinical Sciences, Tokyo, Japan \\ ${ }^{14}$ National Cerebral and Cardiovascular Center, Osaka, Japan \\ ${ }^{15}$ Teikyo Academic Research Center, Teikyo University, Tokyo, Japan \\ ${ }^{16}$ Department of Cardiovascular Medicine, Tohoku University Graduate School of Medicine, Sendai, Japan \\ ${ }^{17}$ Chiba University, Chiba, Japan \\ ${ }^{18}$ Department of Cardiovascular Medicine, Kyoto University Graduate School of Medicine, Kyoto, Japan \\ ${ }^{19}$ St. Hill Hospital, Yamaguchi, Japan \\ ${ }^{20}$ Jichi Medical University, Tochigi, Japan
}

Aim: The association between high-density lipoprotein cholesterol (HDL-C) level after statin therapy and cardiovascular events in patients with stable coronary artery disease (CAD) remains unclear. Thus, in this study, we sought to determine how HDL-C level after statin therapy is associated with cardiovascular events in stable CAD patients.

Methods: From the REAL-CAD study which had shown the favorable prognostic effect of high-dose pitavastatin in stable CAD patients with low-density lipoprotein cholesterol (LDL-C) $<120 \mathrm{mg} / \mathrm{dL}, 9,221$ patients with HDL-C data at baseline and 6 months, no occurrence of primary outcome at 6 months, and reported non-adherence for pitavastatin, were examined. The primary outcome was a composite of cardiovascular death, non-fatal myocardial infarction, non-fatal ischemic stroke, or unstable angina requiring emergent admission after 6 months of randomization. Absolute difference and ratio of HDL-C levels were defined as (those at 6 months-at baseline) and (absolute difference/baseline) $\times 100$, respectively.

Results: During a median follow-up period of 4.0 (IQR 3.2-4.7) years, the primary outcome occurred in 417 (4.5\%) patients. The adjusted risk of all HDL-C-related variables (baseline value, 6 -month value, absolute, and relative changes) for the primary outcome was not significant (hazard ratio [HR] $0.99,95 \%$ confidence interval [CI] 0.91-1.08, HR 1.03, 95\% CI 0.94-1.12, HR 1.05, 95\% CI 0.98-1.12, and HR 1.08, 95\% CI 0.94-1.24, respectively). Furthermore, adjusted HRs of all HDL-C-related variables remained non-significant for the primary outcome regardless of on-treatment LDL-C level at 6 months.

Conclusions: After statin therapy with modestly controlled LDL-C, HDL-C level has little prognostic value in patients with stable CAD.

Key words: Lipids, Secondary prevention, Stable coronary artery disease, Statin, High-density lipoprotein cholesterol Advance Publication Journal of Atherosclerosis and Thrombosis 


\section{Introduction}

Statins have been identified as the most common and effective low-density lipoprotein cholesterol (LDL-C) lowering agents, which are also effective in reducing the risk of major cardiovascular (CV) events such as CV death, non-fatal myocardial infarction, and non-fatal ischemic stroke ${ }^{1,2)}$. The favorable effects of statin therapy for primary and secondary prevention of atherosclerotic cardiovascular disease (ASCVD) have been confirmed, and they are even used worldwide as one of the most important guidelinedirected medical therapies for ASCVD. In particular, an LDL-C-lowering strategy with high-intensity statin therapy is recommended for secondary prevention or primary prevention in patients with high-risk ASCVD in the current guidelines ${ }^{3-5}$.

It has been widely accepted that high-density lipoprotein cholesterol (HDL-C) level is inversely associated with the risk of $\mathrm{CV}$ events in the general population ${ }^{6-11)}$. However, several studies have demonstrated that general subjects with an extremely high as well as low HDL-C level had paradoxically increased mortality ${ }^{12-14)}$ or that there was no relationship between HDL-C level and CV event in patients with coronary artery diseases $(\mathrm{CAD})^{15}$ ) as well as the general population ${ }^{16,17}{ }^{17}$. In terms of patients with stable coronary artery disease treated with statins for secondary prevention, a post-hoc analysis of the Treating to New Targets (TNT) study demonstrated that HDL-C level had a significant inverse association with subsequent major $\mathrm{CV}$ events ${ }^{18}$. However, there have been few reports supporting this finding ${ }^{19)}$.

\section{Aim}

In this study, we sought to examine whether HDL-C level after statin therapy was associated with subsequent $\mathrm{CV}$ events in patients with stable CAD with modestly controlled LDL-C.

\section{Methods}

\section{Study Design and Population}

Data from the Randomized Evaluation of Aggressive or Moderate Lipid Lowering Therapy with Pitavastatin in Coronary Artery Disease (REAL-CAD) study were analyzed. Details of the REAL-CAD study have been described previously ${ }^{20)}$. Briefly, the REAL-
CAD study is a prospective, multicenter, randomized, open-label, blinded endpoint, physician-initiated, superiority trial, which aims to determine whether high-dose ( $4 \mathrm{mg} /$ day) compared with low-dose $(1 \mathrm{mg} /$ day) pitavastatin therapy could reduce $\mathrm{CV}$ events in Japanese patients with stable CAD. Stable CAD was defined as a history of acute coronary syndrome (ACS) or coronary revascularization $>3$ months ago or a clinical diagnosis of CAD with angiographically documented coronary artery stenosis of at least $75 \%$ diameter narrowing as per the American Heart Association classification ${ }^{211}$. Enrolled patients received pitavastatin $1 \mathrm{mg} /$ day orally for a run-in period of at least 1 month. We then excluded patients with LDL-C $\geq 120 \mathrm{mg} / \mathrm{dL}$ throughout the run-in period, onset of ACS and/or coronary revascularization within the past 3 months, poor adherence to statin therapy, occurrence of primary endpoint events, or other adverse events prohibiting continuation of the study during the run-in period. After the run-in period, eligible patients were randomized in a 1-to-1 fashion to oral pitavastatin, either high dose or low dose. Ethics approval was granted by the Public Health Research Foundation ethics review committee and by ethics committees at all participating sites. All participants provided written informed consent. The study was conducted in accordance with the Declaration of Helsinki.

This present study was a post-hoc analysis of the REAL-CAD study. Among the 14,774 participants enrolled, we excluded 1,720 patients with withdrawal or missing consent or for other reasons. Then, 13,054 patients with LDL-C $<120 \mathrm{mg} / \mathrm{dL}$ on pitavastatin 1 $\mathrm{mg} /$ day at any time during the run-in period were randomized to either pitavastatin $1 \mathrm{mg} /$ day or $4 \mathrm{mg} /$ day. We then excluded 641 patients with withdrawal or missing consent or after failing to meet the eligibility criteria. Among the full analysis set of 12,413 patients in the main study, we excluded 492 patients who had no HDL-C data at 6 months, 816 patients with reported non/poor adherence to the study drug during the initial 6 months after randomization, 131 patients who had the primary outcome within 6 months, and 1,753 patients with missing covariates. Ultimately, 9,221 patients were examined (Fig. 1).

\section{Serum Lipid Levels and Other Blood Tests}

Blood samples were collected in each hospital to determine the fasting lipid levels and the patient's

Address for correspondence: Toshiyuki Nagai, Department of Cardiovascular Medicine, Faculty of Medicine and Graduate School of Medicine, Hokkaido University, Sapporo, Japan. Kita 15, Nishi 7, Kita-ku, Sapporo, Hokkaido 060-8638, Japan. E-mail: nagai@med.hokudai.ac.jp

Received: August 11, 2020 Accepted for publication: November 3, 2020

Copyright@2021 Japan Atherosclerosis Society

This article is distributed under the terms of the latest version of CC BY-NC-SA defined by the Creative Commons Attribution License.

\section{Advance Publication Journal of Atherosclerosis and Thrombosis}




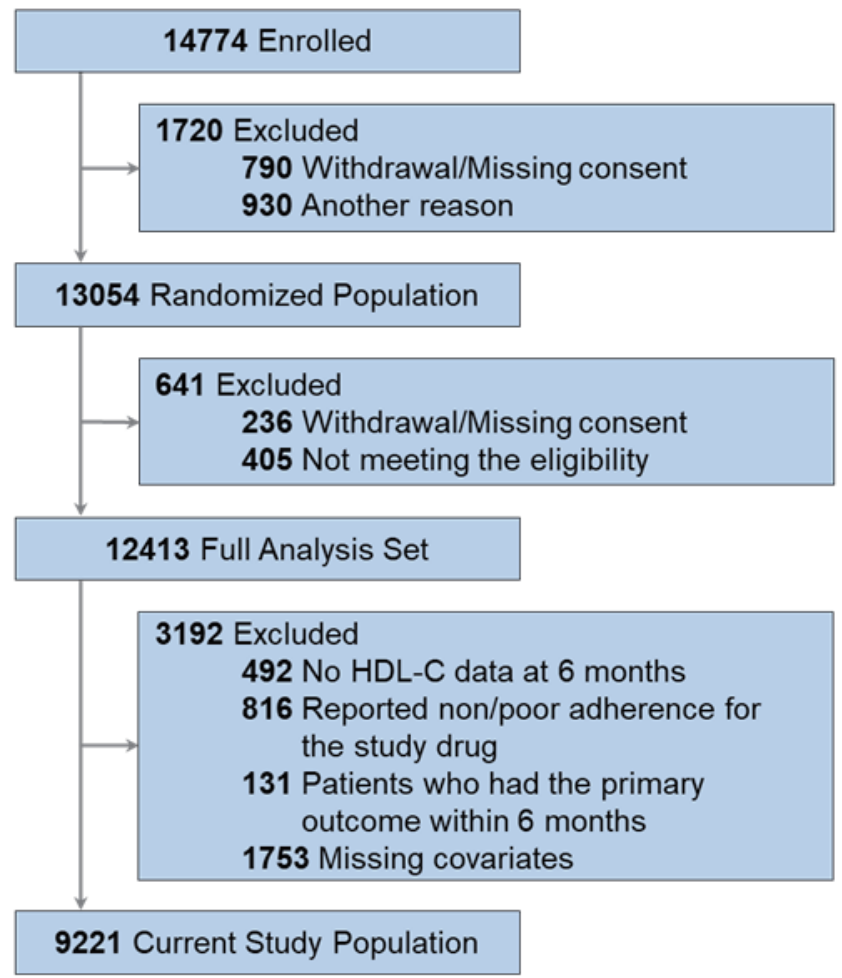

Fig. 1. Flow of patients through study

standard clinical profile as described previously ${ }^{22)}$. Serum lipid levels including LDL-C, total cholesterol, triglyceride (TG), and HDL-C, as well as other blood tests such as red blood cells, white blood cells, hemoglobin A1c, and high-sensitivity C-reactive protein (hsCRP), were measured at baseline and at 6 months after randomization. Values of LDL-C at baseline and at 6 months were derived from central laboratory measurements using the Friedewald equation. If a value from central laboratory measurements was missing or not calculable, a value obtained from insurance-covered measurement was used instead. If that was also missing, the value was not imputed from other data but was handled as a missing value. The main assay method and maximum inter- and intra-assay coefficients of variation in each blood maker were shown in Supplementary Table 1.

\section{Clinical Outcomes}

The primary outcome of interest was a composite of CV death, non-fatal myocardial infarction, nonfatal ischemic stroke, or unstable angina requiring emergent admission after 6 months from randomization, consistent with the primary analysis of the trial ${ }^{20)}$. The secondary outcome of interest was defined as a composite of the primary endpoint event and clinically indicated coronary revascularization excluding target lesion revascularization for lesions treated at prior percutaneous coronary intervention.

\section{Statistical Analysis}

Continuous variables are presented as median and interquartile range (IQR), categorical variables are expressed as numbers and percentages. Study patients were divided into three groups according to their baseline HDL-C level as follows: low HDL-C group (HDL-C $<40 \mathrm{mg} / \mathrm{dL}, n=1660$ ), intermediate HDL-C group (HDL-C 40-79 mg/dL, $n=7321$ ), and high HDL-C group (HDL-C $\geq 80 \mathrm{mg} / \mathrm{dL}, n=240$ ). Comparisons of differences across these three groups were made using Cochran-Armitage test for trend. To evaluate the influence of HDL-C level after statin therapy on the primary and secondary outcomes and each component of the composite endpoint including CV death, non-fatal myocardial infarction, non-fatal ischemic stroke, and unstable angina requiring emergent admission after 6 months, we constructed landmark Cox-proportional hazards regression models, which evaluated the clinical events during the entire follow-up period starting at 6 months after randomization. We then expressed the hazard ratio (HR) and its 95\% confidence interval (CI) which was adjusted using 18 selected clinically relevant riskadjusting variables listed in Table 1. We categorized 
Table 1. Patients Characteristics

\begin{tabular}{|c|c|c|c|c|c|}
\hline Variables & Overall $(n=9221)$ & \multicolumn{3}{|c|}{ HDL-C } & $p$ for trend \\
\hline Age, $y$ & $70(63-75)$ & $70(64-75)$ & $69(63-75)$ & $69(64-75)$ & 0.91 \\
\hline Age of $\geq 65$ years, $n(\%)^{*}$ & $6249(68)$ & $1159(70)$ & $4924(67)$ & $166(69)$ & 0.11 \\
\hline Body mass index, $\mathrm{kg} / \mathrm{m}^{2}$ & $24.4(22.4-26.6)$ & $25.2(23.2-27.3)$ & $24.2(22.3-26.4)$ & $22.7(20.7-24.8)$ & $<0.001$ \\
\hline Body mass index $<25, n(\%)^{*}$ & $5313(58)$ & $785(47)$ & $4340(59)$ & $188(78)$ & $<0.001$ \\
\hline Systolic blood pressure, $\mathrm{mm} \mathrm{Hg}$ & $127(117-137)$ & $126(116-137)$ & $127(117-137)$ & $129(118-137)$ & 0.049 \\
\hline Diastolic blood pressure, $\mathrm{mm} \mathrm{Hg}$ & $72(66-80)$ & $72(65-80)$ & $72(66-80)$ & $72(68-80)$ & 0.010 \\
\hline \multicolumn{6}{|l|}{ Cardiovascular history, $n(\%)$} \\
\hline Stroke* & $735(8)$ & $158(10)$ & $558(8)$ & $19(8)$ & 0.020 \\
\hline Diabetes mellitus ${ }^{*}$ & $3711(40)$ & $969(42)$ & $948(40)$ & $834(35)$ & $<0.001$ \\
\hline Hypertension ${ }^{*}$ & $7033(76)$ & $747(45)$ & $2885(40)$ & $79(33)$ & $<0.001$ \\
\hline Chronic kidney disease, $n(\%)$ & & & & & $<0.001$ \\
\hline Stage 1 & $671(7)$ & $68(4)$ & $572(8)$ & $31(13)$ & \\
\hline Stage 2 & $5244(57)$ & $850(51)$ & $4255(58)$ & $139(58)$ & \\
\hline Stage 3 & $3158(34)$ & $691(42)$ & $2399(33)$ & $68(28)$ & \\
\hline Stage 4 & $137(2)$ & $47(3)$ & $88(1)$ & $2(1)$ & \\
\hline Stage 5 & $11(0.1)$ & $4(0.2)$ & $7(0.1)$ & $0(0)$ & \\
\hline$\geq$ Stage $3^{*}$ & $3306(36)$ & $742(45)$ & $2494(34)$ & $70(29)$ & $<0.001$ \\
\hline Red blood cell, $10^{4} / \mu \mathrm{L}$ & $448(415-479)$ & $452(420-488)$ & $448(415-478)$ & $422(402-455)$ & $<0.001$ \\
\hline White blood cell, $/ \mu \mathrm{L}$ & $5700(4800-6790)$ & $6100(5100-7100)$ & $5650(4800-6700)$ & $5200(4395-5950)$ & $<.001$ \\
\hline Total cholesterol, mg/dL & $166(150-183)$ & $155(140-171)$ & $168(152-183)$ & $193(175-209)$ & $<0.001$ \\
\hline LDL-C, mg/dL ${ }^{*}$ & $88(75-101)$ & $84(71-97)$ & $88(76-102)$ & $91(75-106)$ & $<0.001$ \\
\hline HDL-C, mg/dL & $49(42-57)$ & $37(34-41)$ & $51(45-59)$ & $80(73-90)$ & $<0.001$ \\
\hline Triglycerides, $\mathrm{mg} / \mathrm{dL}$ & $124(89-175)$ & $153(112-212)$ & $119(86-167)$ & $84(63-127)$ & $<0.001$ \\
\hline Triglycerides $\geq 150 \mathrm{mg} / \mathrm{dL}, n(\%)^{*}$ & $3255(35.3)$ & $862(52)$ & $2361(32)$ & $32(13)$ & $<0.001$ \\
\hline LDL-C at 6 months, mg/dL & $80(66-94)$ & $74(60-87)$ & $81(67-95)$ & $84(72-101)$ & $<0.001$ \\
\hline HDL-C at 6-month, mg/dL & $49(42-58)$ & $36(33-38)$ & $51(45-59)$ & $85(82-91)$ & $<0.001$ \\
\hline High-sensitivity C-reactive Protein, mg/dL & $0.51(0.25-1.18)$ & $0.68(0.34-1.52)$ & $0.48(0.23-1.10)$ & $0.33(0.18-0.87)$ & 0.005 \\
\hline $\begin{array}{l}\text { High-sensitivity C-reactive Protein } \\
\geq 1.0 \mathrm{mg} / \mathrm{L} \text { at } 6 \text { months, } n(\%)^{*}\end{array}$ & $2469(26.8)$ & $614(37)$ & $1816(25)$ & $39(16)$ & $<0.001$ \\
\hline Hemoglobin A1c, \% & $5.7(5.3-6.2)$ & $5.7(5.4-6.3)$ & $5.6(5.3-6.2)$ & $5.5(5.2-6.0)$ & $<0.001$ \\
\hline
\end{tabular}

Data are median (interquartile range), or $n(\%)$. ACE, angiotensin-converting enzyme; ARBs, angiotensin II receptor blockers; HDL-C, highdensity lipoprotein cholesterol; LDL-C, low-density lipoprotein cholesterol.

* Covariates included in the multivariate Cox-proportional hazards model. 
age, body mass index (BMI), hsCRP, and TG as clinically meaningful reference values and regarded the randomized statin dose group as a stratified factor.

To explore the shape of the association of HDLC-related variables (baseline value, 6 months value, absolute, and relative changes) and the primary and secondary outcomes, we fitted penalized splines with an AIC-based penalty term. Absolute and relative changes of HDL-C level were defined as (6-month value-baseline value) and (absolute change/baseline value) $\times 100$, respectively. Crude and adjusted cumulative incidence (1-survival) curves were also plotted by statin dose ${ }^{23)}$.

All tests were two-tailed, and a value of $p<0.05$ was considered statistically significant. All statistical analyses were conducted by a statistician (Isao Yokota) using SAS software version 9.4 (SAS Institute, Cary, North Carolina, USA) and R ver. 3.5.1.

\section{Results}

\section{Characteristics of Study Population}

The baseline characteristics of the total 9,221 studied patients are summarized in Table 1. Patients with lower HDL-C level were predominantly male, current smokers, and had higher BMI, higher prevalence of prior myocardial infarction, stroke, diabetes mellitus, and hypertension, and had higher use of angiotensin-converting enzyme inhibitors or angiotensin II receptor blockers, beta-blockers, and dual antiplatelet therapy, and had higher levels of TG, hsCRP, and hemoglobin A1c; and had lower prevalence of malignancy and lower renal function, total cholesterol, and LDL-C levels than those with higher HDL-C level. There were no significant differences across the three groups in terms of age and the prevalence of atrial fibrillation.

\section{HDL-C Level After Statin Therapy and Clinical Outcomes}

During a median follow-up period of 4.0 (IQR $3.2-4.7)$ years, the primary and secondary outcomes occurred in $417(4.5 \%)$ and $812(8.8 \%)$ patients, respectively. There was no significant difference in crude and adjusted cumulative incidence of the primary outcome among the three groups of HDL-C level at 6 months (Fig. 2A and 2B). Furthermore, the adjusted risks of all the HDL-C-related variables (baseline value, 6-month value, absolute, and relative changes) for the primary outcome were not deemed significant (Fig. 3). Interaction tests indicated that relationships between all HDL-C-related variables and the risk of primary outcome did not depend on gender $(P$ for interaction $=0.39$ [baseline value], $P$ for interaction $=0.12$ [6-month value], $P$ for interaction $=$ 0.23 [absolute changes], and $P$ for interaction $=0.37$ [relative changes]) and BMI ( $P$ for interaction $=0.997$, [baseline value], $P$ for interaction $=0.99,[6$ - - onth value], $P$ for interaction $=0.99$, [absolute changes], and $P$ for interaction $=0.89$, [relative changes]). In addition, there was also no significant difference in crude and adjusted cumulative incidence of the secondary outcome among the groups (Fig. $2 \mathrm{C}$ and 2D). The adjusted risks of all HDL-C-related variables (baseline value, 6-month value, absolute, and relative changes) for the secondary outcome were also determined to be not significant (Fig.4). The adjusted risks of all HDL-C-related variables for each component of the composite endpoint including CV death, non-fatal myocardial infarction, non-fatal ischemic stroke, and unstable angina requiring emergent admission after 6 months were also not significant (Supplementary Fig. 1-4).

The adjusted HRs of all HDL-C-related variables (baseline value, 6-month value, absolute, and relative changes) with an increase by $10 \mathrm{mg} / \mathrm{dL}$ (or $10 \%$ in the case of relative HDL-C change) remained nonsignificant for both the primary and secondary outcomes at each on-treatment LDL-C level at 6 months ( $<70 \mathrm{mg} / \mathrm{dL}, 70-100 \mathrm{mg} / \mathrm{dL}$, and $\geq 100 \mathrm{mg} /$ dL) (Supplementary Fig. 5-10). Moreover, there was no significant association between all the HDL-Crelated variables and the primary and secondary outcomes both in the low-dose $(1 \mathrm{mg} /$ day $)$ and highdose ( $4 \mathrm{mg} /$ day) groups (Supplementary Fig. 11 and 12).

\section{Discussion}

The major finding of this present study was that HDL-C level after pitavastatin therapy was not significantly associated with $\mathrm{CV}$ events in patients with stable CAD. We also found that there was no significant association between all the HDL-C-related variables (baseline value, 6-month value, absolute, and relative changes) and subsequent $\mathrm{CV}$ events in stable CAD patients regardless of their on-treatment LDL-C level $(<70 \mathrm{mg} / \mathrm{dL}, 70-100 \mathrm{mg} / \mathrm{dL}$, and $\geq 100 \mathrm{mg} /$ $\mathrm{dL})$ at 6 months. Moreover, no significant relationship was determined between all the HDL-C-related variables and $\mathrm{CV}$ events both in the low-dose $(1 \mathrm{mg} /$ day) and high-dose ( $4 \mathrm{mg} /$ day) groups. These findings suggest that unlike LDL-C, HDL-C level was not related to worse clinical outcomes in patients with stable CAD who were treated with pitavastatin and have a modestly controlled LDL-C level.

Over the past several decades, it has been widely accepted that HDL-C plays an important role in 
A

Primary Outcome (Crude)

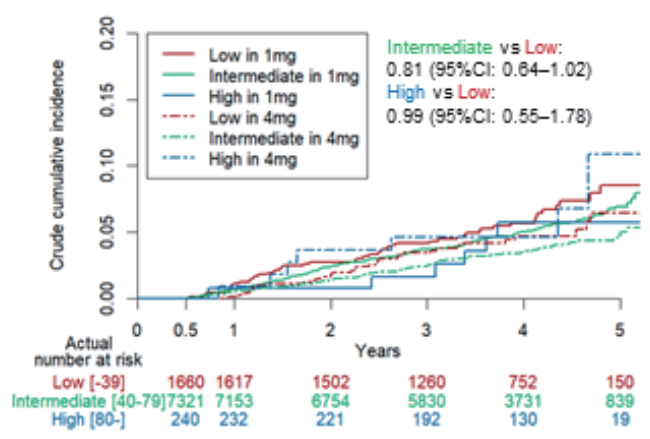

\section{Secondary Outcome (Crude)}

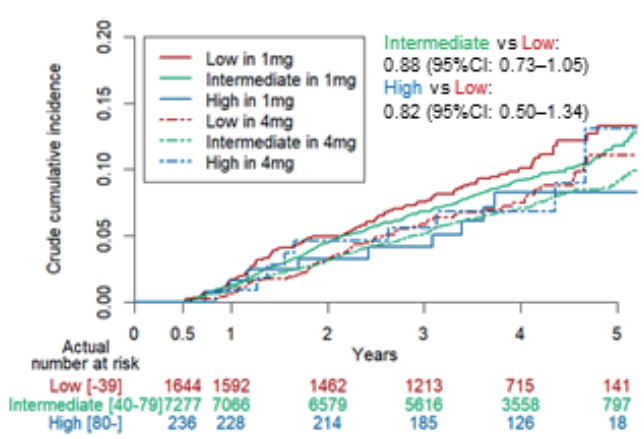

B Primary Outcome (Adjusted)

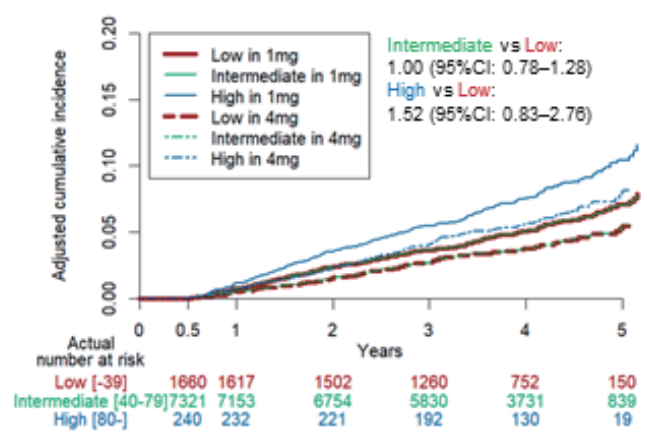

\section{Secondary Outcome (Adjusted)}

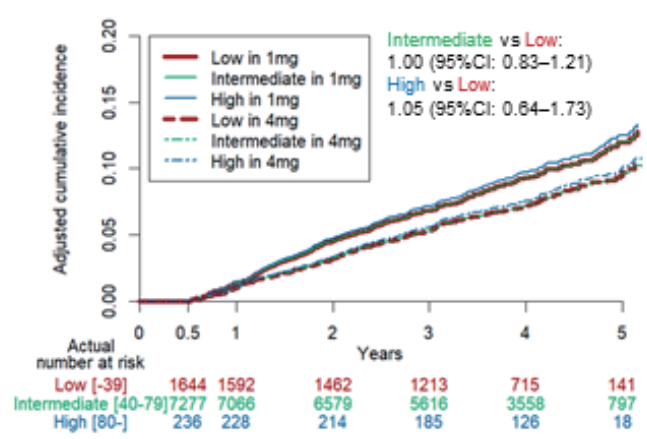

Fig. 2. Landmark analysis for primary and secondary outcome

Solid line indicates low-dose pitavastatin group ( $1 \mathrm{mg} /$ day); dotted line, high-dose pitavastatin group ( $4 \mathrm{mg} /$ day). The crude and adjusted hazard ratios with $95 \%$ confidence interval are shown.

reducing CV risk and mortality, because major studies including the Framingham Study demonstrated that HDL-C level was inversely correlated with the risk of $\mathrm{CV}$ events in the general population ${ }^{6-11)}$. Therefore, HDL-C has been considered a "good cholesterol," and having a therapeutic target to prevent CV events and to increase HDL-C was believed to be a successful strategy to reduce CV events or mortality. Notably, human apolipoprotein A-I (the major protein component of HDL) transgenic mice fed an atherogenic diet, with high plasma concentrations of HDL-C and apolipoprotein A-I, were protected from the development of fatty streak lesions in their $\operatorname{arteries}^{24)}$. Although the mechanism of HDL-C's protective effect against ASCVD is complex and not fully elucidated, several hypotheses have been proposed $^{25)}$. In general, HDL-C has a specific function in reverse cholesterol transport, which is considered to play an important role in cholesterol homeostasis and may be responsible for some of its protective effects against atherosclerosis by removing cholesterol from peripheral tissues or delivering cholesterol to the liver or steroidogenic organs through binding of apolipoprotein A-I to the high-affinity HDL receptor scavenger receptor $B$ type $\mathrm{I}^{26-28)}$. Moreover, HDL-C has been determined to have multiple anti-atherogenic properties such as antiinflammatory, antioxidative, anti-thrombotic, antiapoptotic, vasodilatory, host-defense, and immunemodulatory functions, which may further strengthen CV protection ${ }^{29-33)}$.

This inverse association was also found in stable CAD patients with statin therapy, according to a posthoc analysis of the TNT trial ${ }^{18)}$. In the analysis, an increase in HDL-C level of $1 \mathrm{mg} / \mathrm{dL}$ at 3 months after randomization significantly reduced the risk of major 


\section{A At Baseline}

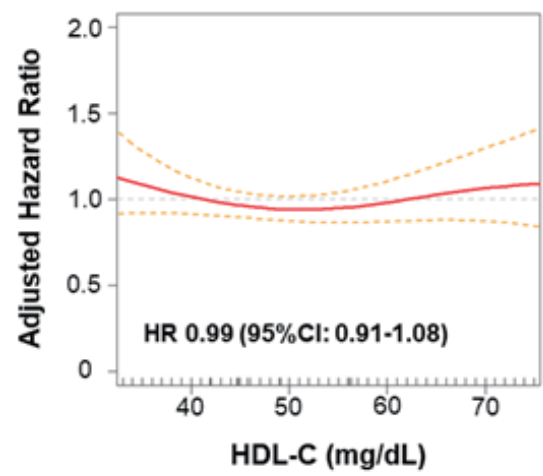

C Absolute Change

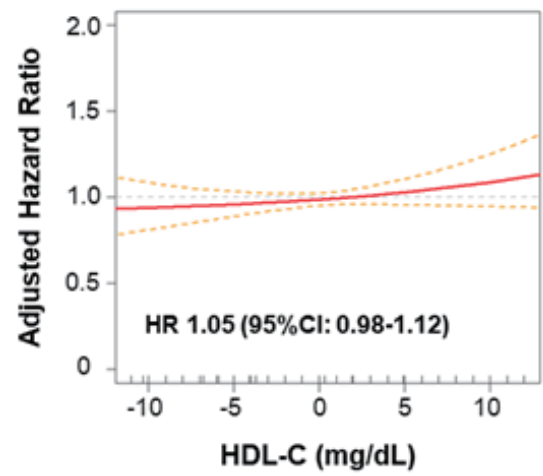

B At 6 Months
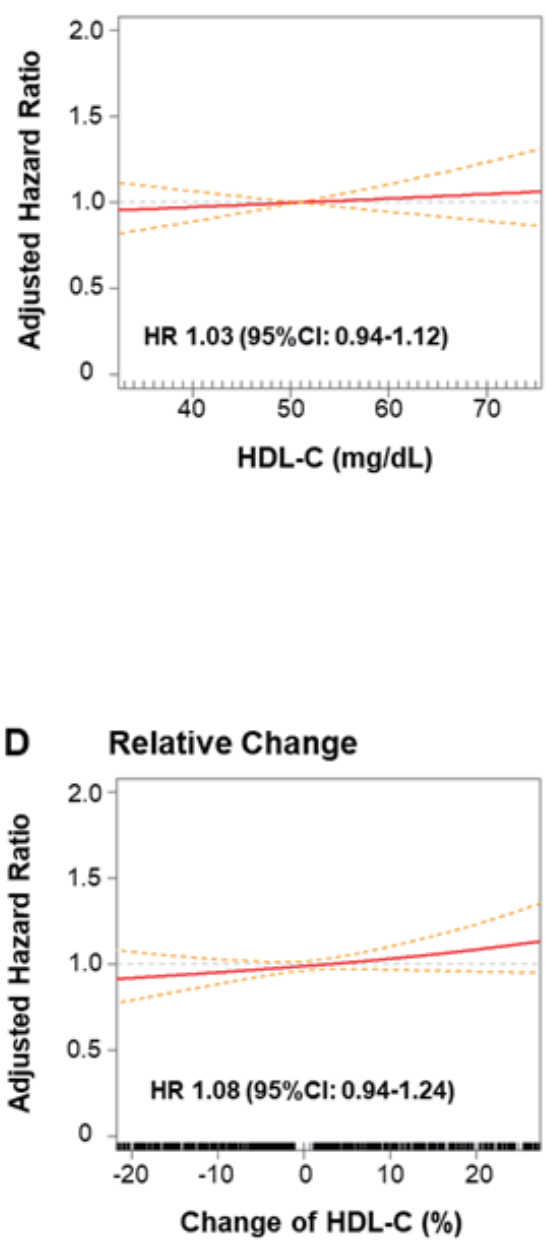

Fig. 3. Adjusted risks of HDL-C values for primary outcome

Red line indicates hazard ratio with penalized smoothing splines adjusted by covariates shown in Table 1. Dashed yellow line indicates its $95 \%$ confidence interval. HR, hazard ratio.

CV events by $1.1 \%$ after adjustments for covariates in 9,732 stable CAD patients treated with atorvastatin. Interestingly, our present findings differ from those in the TNT trial. There are several possible reasons for this difference. First, the era of enrolment in the TNT trial was more than 10 years before the REAL-CAD study. During this period, treatment for stable CAD improved dramatically, including procedures for revascularization, the quality of coronary stents, and shortened dual antiplatelet therapy, which would affect clinical outcomes in patients with stable CAD. Second, the baseline characteristics of the population of the TNT trial such as BMI, prior myocardial infarction, and LDL-C level seem to be more complex conditions than those in the present study. In fact, the TNT trial had a higher incidence of major CV events than the REAL-CAD study $(9.7 \%$ for 5 years vs. $4.5 \%$ for 4 years), although the setting of the primary outcome was similar between the studies.

In terms of the modification of HDL-C level, drugs increasing HDL-C level, such as niacin, cholesteryl ester transfer protein (CETP) inhibitors, and fenofibrate, failed to show significant favorable effects on CV outcomes ${ }^{34-37)}$. More importantly, extremely high HDL-C is paradoxically associated with increased $\mathrm{CV}$ events ${ }^{12,13)}$. One of the reasons is thought to be genetic variants, which may have harmful effects causing worse clinical outcomes. For example, as one of the typical genetic variants, there are certain mutations in lipid transfer proteins, such as CETP, which are known to be associated with both high-risk ASCVD and high HDL-C level ${ }^{38)}$. Notably, the ILLUMINATE trial demonstrated that torcetrapib as a CETP inhibitor significantly increased mortality compared to placebo rather than reduced major $\mathrm{CV}$ events, despite increased HDL-C level in the 


\section{A At Baseline}

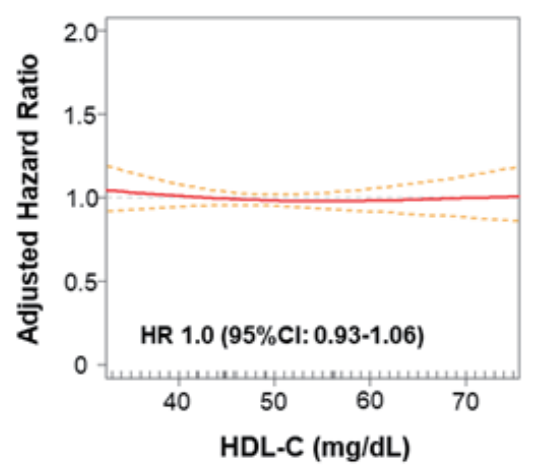

C Absolute Change

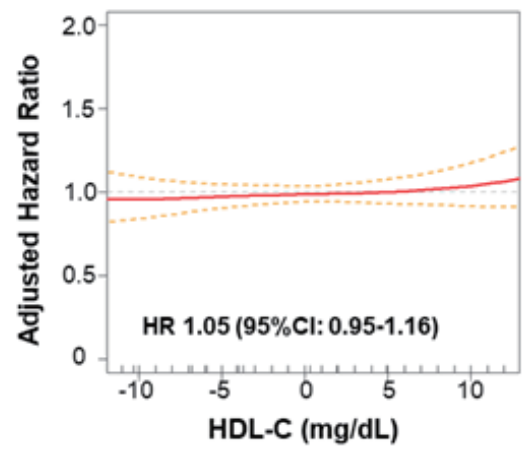

B At 6 Months

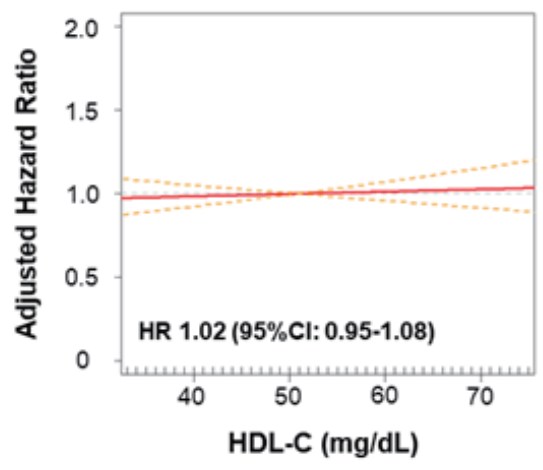

D Relative Change

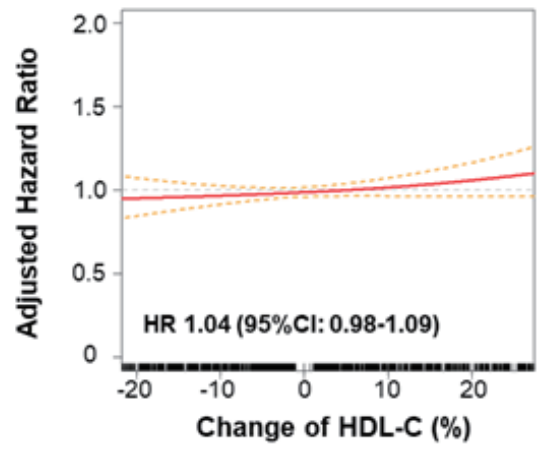

Fig.4. Adjusted risks of HDL-C values for secondary outcome

Red line indicates hazard ratio with penalized smoothing splines adjusted by covariates shown in Table 1. Dashed yellow line indicates its $95 \%$ confidence interval. HR, hazard ratio.

torcetrapib arm ${ }^{34)}$.

Based on these findings, it can be thought that the quality or function rather than the quantity of HDL-C may be important for the risk of CV events. HDL-C may provide CV protection by promoting reverse cholesterol transport from macrophages. Khera et al. demonstrated that cholesterol efflux capacity from macrophages, a metric of HDL-C function, has a strong inverse association with both carotid intimamedia thickness and the likelihood of angiographic $\mathrm{CAD}$, independent of the HDL-C level ${ }^{39)}$. Moreover, there are several reports that the quantity of HDL-C was not related to $\mathrm{CV}$ events ${ }^{40-42)}$. From a sub-analysis of the JUPITER trial, the quantity of HDL-C could not predict $\mathrm{CV}$ risk among adults without diabetes or previous CV disease and treated with statin therapy, although the quantity of HDL-C was significantly associated with CV events risk in the placebo arm (without statin therapy) ${ }^{42}$. Thus, statin therapy could improve the quality or function of HDL-C. While a recent study reported HDL-C function was unaltered by atorvastatin treatment ${ }^{43)}$, pitavastatin may have different efficacies from atorvastatin. As compared to atorvastatin, pitavastatin has a more favorable effect on glycemic status ${ }^{44)}$, and it further provides greater improvement of endothelial function ${ }^{45}$ and greater increases in HDL-C and apoprotein A-1 levels ${ }^{46)}$. Notably, a recent study ${ }^{47)}$ demonstrated that as compared to atorvastatin (10 $\mathrm{mg} /$ day $)$, pitavastatin therapy $(2 \mathrm{mg} /$ day) can significantly reduce $\mathrm{CV}$ events in hypercholesterolemic patients with one or more risk factors for atherosclerotic diseases despite similar effects on HDL-C levels. Regarding effects on function of HDL-C, pitavastatin promoted the early step of reverse cholesterol transport by increasing the pre $\beta 1$-HDL disappearance rate $^{48)}$. Moreover, pitavastatin could increase cholesterol efflux capacity of the isolated HDL fraction and antioxidative actions

\section{Advance Publication Journal of Atherosclerosis and Thrombosis}


related to enzyme paraoxonase-1. Pitavastatin may increase the anti-atherogenic properties of HDL particles ${ }^{49)}$. These findings could support the effect of statins to improve the function or quality of HDL-C. In fact, the period of statin therapy was 3 months longer in the REAL-CAD study than in the post-hoc analysis of the TNT trial. The difference in the timing of analysis of HDL-C level might have influenced the further improvement of the quality/function of HDL$\mathrm{C}$, resulting in weakening the prognostic significance of HDL-C level in the REAL-CAD study.

In this present study, all the HDL-C-related variables (baseline value, 6-month value, absolute, and relative change) were confirmed to have no significant association with $\mathrm{CV}$ events in stable $\mathrm{CAD}$ patients, regardless of their on-treatment LDL-C level or dose of pitavastatin. It is noteworthy that all 9,221 eligible patients in our study population had stable CAD with pitavastatin treatment for at least 6 months as secondary prevention. From this point of view, we believe our findings provide clinically relevant information from a large population supporting that it would be unnecessary to consider the on-statin treatment HDL-C level in stable CAD patients with a modestly controlled LDL-C level (i.e., median [IQR]; 88 [75-101] mg/dL at baseline, 80 [66-94] mg/dL at 6 months from randomization) for the association with subsequent CV outcomes. Further prospective clinical trials focusing on the quality and function rather than the quantity of $\mathrm{HDL}-\mathrm{C}$ in stable $\mathrm{CAD}$ patients treated with a statin are warranted in order to fully elucidate the role of HDL-C as a residual risk for secondary prevention.

\section{Limitations}

There are several potential limitations of this present study, which should be acknowledged. First, this study is a post-hoc analysis and provides only associative evidence, not causative evidence. Second, there was unavoidable selection bias because 3,192 $(25.7 \%)$ patients were excluded from the full analysis set of 12,413 patients in the REAL-CAD study. Among these, 2,608 patients had both their HDL-C value and outcome data. We then compared the HDL-C level at 6 months and incidence of primary outcome between the study patients $(n=9,221)$ and those excluded $(n=2,608)$. These variables were similar between the study patients and those excluded (HDL-C; 49 [42-58] versus 50 [42-58] $\mathrm{mg} / \mathrm{dL}$, $p=0.07$, and incidence of primary outcome; 417 [4.5\%] versus 102 [3.9\%], $p=0.18)$. Thus, we speculated that the HDL-C level was not associated with CV events even when we do not exclude 3,192 patients from the analysis. Third, there were no data regarding the function or quality of HDL-C. Fourth, participants were recruited at 733 sites in Japan, and the measuring method and the inter-assay and intraassay coefficient of variations for each assay that determines each blood marker were different in each site. Finally, there may have been other differences in variables (e.g., the prevalence of metabolic syndrome, serum uric acid, and troponin T) that were not evaluated but that could have affected the results of the analysis.

\section{Conclusion}

HDL-C level after statin therapy was not associated with subsequent $\mathrm{CV}$ events in patients with stable CAD. It may be unnecessary to consider the quantity of on-statin treatment HDL-C for secondary prevention.

\section{Acknowledgment}

We acknowledge the support of Retsu Fujita, MS (Innovation and Research Support Center, Graduate School of Medicine, International University of Health and Welfare, Tokyo, Japan) in data management.

\section{Conflict of Interest}

Dr. Omote received research grant from Japan Heart Foundation/Bayer Yakuhin Research Grant Abroad. Dr. Yokota reports no conflicts. Dr. T Nagai received honoraria from Daiichi Sankyo Co., Ltd. and clinical research grant from JSPS KAKENHI Grantin-Aid for Scientific Research and research grants from the Takeda Science Foundation, the Japan Foundation for Aging and Health, and the Uehara Memorial Foundation. Dr. Sakuma received honoraria from GlaxoSmithKline KK and a research funding from Kowa Pharmaceutical Co. Dr. Nakagawa received honoraria from Kowa Pharmaceutical Co Ltd, Takeda Pharmaceutical Co Ltd, Bayer Yakuhin, Ltd, Sanofi KK, Daiichi Sankyo Co, Ltd, Shionogi \& Co, Ltd, Astellas Pharma Inc., MSD KK, Mitsubishi Tanabe Pharma Corp, Sumitomo Dainippon Pharma Co, Ltd, AstraZeneca KK, Amgen Astellas BioPharma KK, Eisai Co, Ltd, Otsuka Pharmaceutical Co, Ltd, Pfizer Japan Inc. Dr. Kamiya reports no conflicts. Dr. Iwata received honoraria from Bayer Yakuhin, Ltd., Daiichi Sankyo Co., Ltd., Kowa Pharmaceutical Co., Ltd. Dr. Miyauchi received honoraria from Sanofi KK, Daiichi Sankyo Co., Ltd., Amgen Astellas BioPharma KK, Bayer Yakuhin, Ltd., Bristol-Myers Squibb Co., Ltd, 
and MSD KK. Dr. Ozaki reports no conflicts. Dr. Hibi reports no conflicts. Dr. Hiro received honoraria from Bayer Yakuhin, Ltd. Dr. Fukumoto received honoraria from Actelion Pharmaceuticals Japan, Ltd, Otsuka Pharmaceutical Co., Ltd., Kowa Company, Ltd., Daiichi Sankyo Co., Ltd., Boehringer Ingelheim Japan Co., Ltd., and research funding from Actelion Pharmaceuticals Japan, Ltd, Sanwa Kagaku Kenkyusho Co., Ltd., Daiichi Sankyo Co., Ltd., Nippon Shinyaku Co., Ltd., Pfizer Japan Inc. and scholarship grants from Actelion Pharmaceuticals Japan, Ltd, Astellas Pharma Inc., Eisai Co, Ltd, MSD KK, Ono Pharmaceutical Co., Ltd., KYUDO COMPANY, Kowa Company, Ltd., Shionogi \& Co, Ltd, Takeda Pharmaceutical Co., Ltd., Teijin Pharma Ltd., Japan Lifeline Co. LTD., Novartis Pharma KK, Pfizer Japan Inc., Bayer Yakuhin, Ltd. MOCHIDA PHARMACEUTICAL CO., LTD. Dr. Mori reports no conflicts. Dr. Hokimoto reports no conflicts. Dr. Ohashi reports no conflicts. Mr. Ohtsu reports no conflicts. Dr. Ogawa reports no conflicts. Dr. Daida received honoraria from Amgen Astellas BioPharma KK, Daiichi Sankyo Co., Ltd., Kowa Pharmaceutical Co., Ltd., MSD KK, and research grant from Canon, and scholarship grant from Otsuka Pharmaceutical Co., Ltd., Sanofi KK, MSD KK, Daiichi Sankyo Co., Ltd., Pfizer Japan Inc., Mitsubishi Tanabe Pharma Corp., Astellas Pharma Inc., Takeda Pharmaceutical Co., Ltd., Teijin Pharma Ltd., Shionogi \& Co., Ltd., Actelion Pharmaceuticals Japan, Ltd. Kowa Pharmaceutical Co., Ltd., Bayer Yakuhin, Ltd., Boehringer Ingelheim Japan Co., Ltd., and courses endowed by Phillips, Resmed, Fukuda Denshi, Asahikasei, Inter-Reha, Takeda Pharmaceutical Co., Ltd. Dr. Iimuro received for data management from Teikyo University. Dr. Shimokawa reports no conflicts. Dr. Saito reports no conflicts. Dr. Kimura reports no conflicts. Dr. Matsuzaki reports no conflicts. Dr. R Nagai received research funding from Kowa Pharmaceutical Co., Ltd. Dr. Anzai received honoraria from Daiichi Sankyo Co., Ltd., Ono Pharmaceutical Co., Ltd., Boehringer Ingelheim Japan Co., Ltd., Bayer's Pharmaceuticals Co., Ltd., and Bristol-Myers Squibb Co., Ltd., and clinical research grant from the Japan Agency for Medical Research and Development, and Daiichi Sankyo Co., Ltd., and scholarship funds from Biotronik Japan Co., Ltd., Medtronic Japan Co., Ltd., Win International Co., Ltd., Medical System Network Co., Ltd., and Hokuyaku Takeyama Holdings, Inc.

\section{References}

1) Baigent, C, Keech, A, Kearney, PM, Blackwell, L, Buck,
G, Pollicino, C, Kirby, A, Sourjina, T, Peto, R, Collins, R and Simes, R: Efficacy and safety of cholesterol-lowering treatment: prospective meta-analysis of data from 90,056 participants in 14 randomised trials of statins. Lancet, 2005; 366: 1267-1278

2) Grundy, SM: HMG-CoA reductase inhibitors for treatment of hypercholesterolemia. N Engl J Med, 1988; 319: 24-33

3) Grundy, SM, Stone, NJ, Bailey, AL, Beam, C, Birtcher, KK, Blumenthal, RS, Braun, LT, de Ferranti, S, FaiellaTommasino, J, Forman, DE, Goldberg, R, Heidenreich, PA, Hlatky, MA, Jones, DW, Lloyd-Jones, D, LopezPajares, N, Ndumele, CE, Orringer, CE, Peralta, CA, Saseen, JJ, Smith, SC, Jr., Sperling, L, Virani, SS and Yeboah, J: 2018 AHA/ACC/AACVPR/AAPA/ABC/ ACPM/ADA/AGS/APhA/ASPC/NLA/PCNA Guideline on the Management of Blood Cholesterol: A Report of the American College of Cardiology/American Heart Association Task Force on Clinical Practice Guidelines. Circulation, 2019; 139: e1082-e1143

4) Catapano, AL, Graham, I, De Backer, G, Wiklund, O, Chapman, MJ, Drexel, H, Hoes, AW, Jennings, CS, Landmesser, U, Pedersen, TR, Reiner, Z, Riccardi, G, Taskinen, MR, Tokgozoglu, L, Verschuren, WMM, Vlachopoulos, C, Wood, DA, Zamorano, JL and Cooney, MT: 2016 ESC/EAS Guidelines for the Management of Dyslipidaemias. Eur Heart J, 2016; 37: 2999-3058

5) Rader, DJ and Hovingh, GK: HDL and cardiovascular disease. Lancet, 2014; 384: 618-625

6) Gordon, T, Castelli, WP, Hjortland, MC, Kannel, WB and Dawber, TR: High density lipoprotein as a protective factor against coronary heart disease. The Framingham Study. Am J Med, 1977; 62: 707-714

7) Castelli, WP, Garrison, RJ, Wilson, PW, Abbott, RD, Kalousdian, S and Kannel, WB: Incidence of coronary heart disease and lipoprotein cholesterol levels. The Framingham Study. JAMA, 1986; 256: 2835-2838

8) Gordon, DJ, Probstfield, JL, Garrison, RJ, Neaton, JD, Castelli, WP, Knoke, JD, Jacobs, DR, Jr., Bangdiwala, S and Tyroler, HA: High-density lipoprotein cholesterol and cardiovascular disease. Four prospective American studies. Circulation, 1989; 79: 8-15

9) Frost, PH, Davis, BR, Burlando, AJ, Curb, JD, Guthrie, GP, Jr., Isaacsohn, JL, Wassertheil-Smoller, S, Wilson, AC and Stamler, J: Serum lipids and incidence of coronary heart disease. Findings from the Systolic Hypertension in the Elderly Program (SHEP). Circulation, 1996; 94: 2381-2388

10) deGoma, EM, Leeper, NJ and Heidenreich, PA: Clinical significance of high-density lipoprotein cholesterol in patients with low low-density lipoprotein cholesterol. J Am Coll Cardiol, 2008; 51: 49-55

11) Di Angelantonio, E, Gao, P, Pennells, L, Kaptoge, S, Caslake, M, Thompson, A, Butterworth, AS, Sarwar, N, Wormser, D, Saleheen, D, Ballantyne, CM, Psaty, BM, Sundstrom, J, Ridker, PM, Nagel, D, Gillum, RF, Ford, I, Ducimetiere, P, Kiechl, S, Koenig, W, Dullaart, RP, Assmann, G, D’Agostino, RB, Sr., Dagenais, GR, Cooper, JA, Kromhout, D, Onat, A, Tipping, RW, Gomez-de-laCamara, A, Rosengren, A, Sutherland, SE, Gallacher, J, Fowkes, FG, Casiglia, E, Hofman, A, Salomaa, V, Barrett- 
Connor, E, Clarke, R, Brunner, E, Jukema, JW, Simons, LA, Sandhu, M, Wareham, NJ, Khaw, KT, Kauhanen, J, Salonen, JT, Howard, WJ, Nordestgaard, BG, Wood, AM, Thompson, SG, Boekholdt, SM, Sattar, N, Packard, C, Gudnason, V and Danesh, J: Lipid-related markers and cardiovascular disease prediction. JAMA, 2012; 307: 2499-2506

12) Madsen, CM, Varbo, A and Nordestgaard, BG: Extreme high high-density lipoprotein cholesterol is paradoxically associated with high mortality in men and women: two prospective cohort studies. Eur Heart J, 2017; 38: 24782486

13) Ko, DT, Alter, DA, Guo, H, Koh, M, Lau, G, Austin, PC, Booth, GL, Hogg, W, Jackevicius, CA, Lee, DS, Wijeysundera, HC, Wilkins, JT and Tu, JV: HighDensity Lipoprotein Cholesterol and Cause-Specific Mortality in Individuals Without Previous Cardiovascular Conditions: The CANHEART Study. J Am Coll Cardiol, 2016; 68: 2073-2083

14) Hirata, A, Sugiyama, D, Watanabe, M, Tamakoshi, A, Iso, H, Kotani, K, Kiyama, M, Yamada, M, Ishikawa, S, Murakami, Y, Miura, K, Ueshima, $\mathrm{H}$ and Okamura, T: Association of extremely high levels of high-density lipoprotein cholesterol with cardiovascular mortality in a pooled analysis of 9 cohort studies including 43,407 individuals: The EPOCH-JAPAN study. J Clin Lipidol, 2018; 12: 674-684.e675

15) Izuhara, M, Ono, K, Shiomi, H, Morimoto, T, Furukawa, Y, Nakagawa, Y, Shizuta, S, Tada, T, Tazaki, J, Horie, T, Kuwabara, Y, Baba, O, Nishino, T, Kita, T and Kimura, T: High-density lipoprotein cholesterol levels and cardiovascular outcomes in Japanese patients after percutaneous coronary intervention: a report from the CREDO-Kyoto registry cohort-2. Atherosclerosis, 2015; 242: 632-638

16) Hirata, T, Sugiyama, D, Nagasawa, SY, Murakami, Y, Saitoh, S, Okayama, A, Iso, H, Irie, F, Sairenchi, T, Miyamoto, Y, Yamada, M, Ishikawa, S, Miura, K, Ueshima, H and Okamura, T: A pooled analysis of the association of isolated low levels of high-density lipoprotein cholesterol with cardiovascular mortality in Japan. Eur J Epidemiol, 2017; 32: 547-557

17) Watanabe, J, Kakehi, E, Kotani, K, Kayaba, K, Nakamura, Y and Ishikawa, S: Isolated low levels of highdensity lipoprotein cholesterol and stroke incidence: JMS Cohort Study. J Clin Lab Anal, 2020; 34: e23087

18) Barter, P, Gotto, AM, LaRosa, JC, Maroni, J, Szarek, M, Grundy, SM, Kastelein, JJ, Bittner, V and Fruchart, JC: HDL cholesterol, very low levels of LDL cholesterol, and cardiovascular events. N Engl J Med, 2007; 357: 13011310

19) Nakazawa, M, Arashi, H, Yamaguchi, J, Ogawa, H and Hagiwara, N: Lower levels of high-density lipoprotein cholesterol are associated with increased cardiovascular events in patients with acute coronary syndrome. Atherosclerosis, 2020; 303: 21-28

20) Taguchi, I, Iimuro, S, Iwata, H, Takashima, H, Abe, M, Amiya, E, Ogawa, T, Ozaki, Y, Sakuma, I, Nakagawa, Y, Hibi, K, Hiro, T, Fukumoto, Y, Hokimoto, S, Miyauchi, K, Yamazaki, T, Ito, H, Otsuji, Y, Kimura, K, Takahashi, J, Hirayama, A, Yokoi, H, Kitagawa, K, Urabe, T, Okada,
Y, Terayama, Y, Toyoda, K, Nagao, T, Matsumoto, M, Ohashi, Y, Kaneko, T, Fujita, R, Ohtsu, H, Ogawa, H, Daida, H, Shimokawa, H, Saito, Y, Kimura, T, Inoue, T, Matsuzaki, M and Nagai, R: High-Dose Versus Low-Dose Pitavastatin in Japanese Patients With Stable Coronary Artery Disease (REAL-CAD): A Randomized Superiority Trial. Circulation, 2018; 137: 1997-2009

21) Austen, WG, Edwards, JE, Frye, RL, Gensini, GG, Gott, VL, Griffith, LS, McGoon, DC, Murphy, ML and Roe, BB: A reporting system on patients evaluated for coronary artery disease. Report of the Ad Hoc Committee for Grading of Coronary Artery Disease, Council on Cardiovascular Surgery, American Heart Association. Circulation, 1975; 51: 5-40

22) Miyauchi, K, Kimura, T, Shimokawa, H, Daida, $H$, Iimuro, S, Iwata, H, Ozaki, Y, Sakuma, I, Nakagawa, Y, Hibi, K, Hiro, T, Fukumoto, Y, Hokimoto, S, Ohashi, Y, Ohtsu, H, Saito, Y, Matsuzaki, M and Nagai, R: Rationale and Design of Randomized Evaluation of Aggressive or Moderate Lipid Lowering Therapy with Pitavastatin in Coronary Artery Disease (REAL-CAD) Trial. Int Heart J, 2018; 59: 315-320

23) Makuch, RW: Adjusted survival curve estimation using covariates. J Chronic Dis, 1982; 35: 437-443

24) Rubin, EM, Krauss, RM, Spangler, EA, Verstuyft, JG and Clift, SM: Inhibition of early atherogenesis in transgenic mice by human apolipoprotein AI. Nature, 1991; 353: 265-267

25) Soria-Florido, MT, Schröder, H, Grau, M, Fitó, M and Lassale, C: High density lipoprotein functionality and cardiovascular events and mortality: A systematic review and meta-analysis. Atherosclerosis, 2020; 302: 36-42

26) Krieger, M: Charting the fate of the "good cholesterol": identification and characterization of the high-density lipoprotein receptor SR-BI. Annu Rev Biochem, 1999; 68: $523-558$

27) Assmann, G and Nofer, JR: Atheroprotective effects of high-density lipoproteins. Annu Rev Med, 2003; 54: 321 341

28) Barter, PJ, Nicholls, S, Rye, KA, Anantharamaiah, GM, Navab, $M$ and Fogelman, AM: Antiinflammatory properties of HDL. Circ Res, 2004; 95: 764-772

29) Mineo, C, Deguchi, H, Griffin, JH and Shaul, PW: Endothelial and antithrombotic actions of HDL. Circ Res, 2006; 98: 1352-1364

30) Hafiane, A and Genest, J: HDL, Atherosclerosis, and Emerging Therapies. Cholesterol, 2013; 2013: 891403

31) Assmann, G and Gotto, AM, Jr.: HDL cholesterol and protective factors in atherosclerosis. Circulation, 2004; 109: Iii8-14

32) Pirillo, A and Catapano, AL: Pitavastatin and HDL: Effects on plasma levels and function(s). Atheroscler Suppl, 2017; 27: e1-e9

33) Bandeali, S and Farmer, J: High-density lipoprotein and atherosclerosis: the role of antioxidant activity. Curr Atheroscler Rep, 2012; 14: 101-107

34) Barter, PJ, Caulfield, M, Eriksson, M, Grundy, SM, Kastelein, JJ, Komajda, M, Lopez-Sendon, J, Mosca, L, Tardif, JC, Waters, DD, Shear, CL, Revkin, JH, Buhr, KA, Fisher, MR, Tall, AR and Brewer, B: Effects of torcetrapib in patients at high risk for coronary events. $\mathrm{N}$ 
Engl J Med, 2007; 357: 2109-2122

35) Landray, MJ, Haynes, R, Hopewell, JC, Parish, S, Aung, T, Tomson, J, Wallendszus, K, Craig, M, Jiang, L, Collins, $\mathrm{R}$ and Armitage, J: Effects of extended-release niacin with laropiprant in high-risk patients. N Engl J Med, 2014; 371: 203-212

36) Boden, WE, Probstfield, JL, Anderson, T, Chaitman, BR, Desvignes-Nickens, P, Koprowicz, K, McBride, R, Teo, K and Weintraub, W: Niacin in patients with low HDL cholesterol levels receiving intensive statin therapy. N Engl J Med, 2011; 365: 2255-2267

37) Ginsberg, HN, Elam, MB, Lovato, LC, Crouse, JR, 3rd, Leiter, LA, Linz, P, Friedewald, WT, Buse, JB, Gerstein, HC, Probstfield, J, Grimm, RH, Ismail-Beigi, F, Bigger, JT, Goff, DC, Jr., Cushman, WC, Simons-Morton, DG and Byington, RP: Effects of combination lipid therapy in type 2 diabetes mellitus. N Engl J Med, 2010; 362: 1563-1574

38) Johannsen, TH, Frikke-Schmidt, R, Schou, J, Nordestgaard, BG and Tybjaerg-Hansen, A: Genetic inhibition of CETP, ischemic vascular disease and mortality, and possible adverse effects. J Am Coll Cardiol, 2012; 60: 2041-2048

39) Khera, AV, Cuchel, M, de la Llera-Moya, M, Rodrigues, A, Burke, MF, Jafri, K, French, BC, Phillips, JA, Mucksavage, ML, Wilensky, RL, Mohler, ER, Rothblat, GH and Rader, DJ: Cholesterol efflux capacity, highdensity lipoprotein function, and atherosclerosis. N Engl J Med, 2011; 364: 127-135

40) Angeloni, E, Paneni, F, Landmesser, U, Benedetto, U, Melina, G, Luscher, TF, Volpe, M, Sinatra, R and Cosentino, F: Lack of protective role of HDL-C in patients with coronary artery disease undergoing elective coronary artery bypass grafting. Eur Heart J, 2013; 34: 3557-3562

41) Silbernagel, G, Schottker, B, Appelbaum, S, Scharnagl, H, Kleber, ME, Grammer, TB, Ritsch, A, Mons, U, Holleczek, B, Goliasch, G, Niessner, A, Boehm, BO, Schnabel, RB, Brenner, H, Blankenberg, S, Landmesser, $\mathrm{U}$ and Marz, W: High-density lipoprotein cholesterol, coronary artery disease, and cardiovascular mortality. Eur Heart J, 2013; 34: 3563-3571

42) Ridker, PM, Genest, J, Boekholdt, SM, Libby, P, Gotto, AM, Nordestgaard, BG, Mora, S, MacFadyen, JG, Glynn, RJ and Kastelein, JJ: HDL cholesterol and residual risk of first cardiovascular events after treatment with potent statin therapy: an analysis from the JUPITER trial. Lancet, 2010; 376: 333-339

43) Muñoz-Hernandez, L, Ortiz-Bautista, RJ, Brito-Córdova,
G, Lozano-Arvizu, F, Saucedo, S, Pérez-Méndez, O, Zentella-Dehesa, A, Dauteuille, C, Lhomme, M, Lesnik, P, Chapman, MJ, Kontush, A and Aguilar Salinas, CA: Cholesterol efflux capacity of large, small and total HDL particles is unaltered by atorvastatin in patients with type 2 diabetes. Atherosclerosis, 2018; 277: 72-79

44) Choi, JY, Choi, CU, Hwang, SY, Choi, BG, Jang, WY, Kim, DY, Kim, W, Park, EJ, Lee, S, Na, JO, Kim, JW, Kim, EJ, Rha, SW, Park, CG, Seo, HS, Chae, SC, Kim, YJ, Cho, MC, Kim, CJ, Kim, HS and Jeong, MH: Effect of Pitavastatin Compared with Atorvastatin andRosuvastatin on New-Onset Diabetes Mellitus in PatientsWith Acute Myocardial Infarction. Am J Cardiol, 2018; 122: 922-928

45) Sakabe, K, Fukuda, N, Fukuda, Y, Wakayama, K, Nada, T, Morishita, S, Shinohara, $H$ and Tamura, Y: Comparisons of short- and intermediate-term effects of pitavastatin versus atorvastatin on lipid profiles, fibrinolytic parameter, and endothelial function. Int J Cardiol, 2008; 125: 136-138

46) Sasaki, J, Ikeda, Y, Kuribayashi, T, Kajiwara, K, Biro, S, Yamamoto, K, Ageta, M, Kobori, S, Saikawa, T, Otonari, $\mathrm{T}$ and Kono, S: A 52-week, randomized, open-label, parallel-group comparison of the tolerability and effects of pitavastatin and atorvastatin on high-density lipoprotein cholesterol levels and glucose metabolism in Japanese patients with elevated levels of low-density lipoprotein cholesterol and glucose intolerance. Clin Ther, 2008; 30: 1089-1101

47) Moroi, M, Nagayama, D, Hara, F, Saiki, A, Shimizu, K, Takahashi, M, Sato, N, Shiba, T, Sugimoto, H, Fujioka, T, Chiba, T, Nishizawa, K, Usui, S, Iwasaki, Y, Tatsuno, I, Sugi, K, Yamasaki, J, Yamamura, S and Shirai, K: Outcome of pitavastatin versus atorvastatin therapy in patients with hypercholesterolemia at high risk for atherosclerotic cardiovascular disease. Int J Cardiol, 2020; 305: 139-146

48) Kawano, M, Nagasaka, S, Yagyu, H and Ishibashi, S: Pitavastatin decreases plasma prebeta1-HDL concentration and might promote its disappearance rate in hypercholesterolemic patients. J Atheroscler Thromb, 2008; 15: 41-46

49) Miyamoto-Sasaki, M, Yasuda, T, Monguchi, T, Nakajima, H, Mori, K, Toh, R, Ishida, T and Hirata, K: Pitavastatin increases HDL particles functionally preserved with cholesterol efflux capacity and antioxidative actions in dyslipidemic patients. J Atheroscler Thromb, 2013; 20: 708-716 
Supplementary Table 1. The maximum values of the inter- and intra-assay coefficient of variations

\begin{tabular}{lccl}
\hline Blood examinations & Inter-assay CV & Intra-assay CV & Assay method \\
\hline Total cholesterol, mg/dL & $2.0 \%$ & $1.6 \%$ & $\begin{array}{l}\text { Hitachi 911 using a cholesterol esterase, } \\
\text { cholesterol oxidase reaction } \\
\text { (Chol R1, Roche Diagnostics Corp.) }\end{array}$ \\
HDL-C, mg/dL & $4.1 \%$ & $3.6 \%$ & $\begin{array}{l}\text { Hitachi } 911 \text { using a cholesterol esterase, } \\
\text { cholesterol oxidase reaction } \\
\text { (Chol R1, Roche Diagnostics Corp.) }\end{array}$ \\
Triglycerides, mg/dL & $3.2 \%$ & $1.3 \%$ & $\begin{array}{l}\text { Glycerol blanked enzymatic method } \\
\text { (Trig/GB, Roche Diagnostics Corp.) }\end{array}$ \\
High-sensitivity CRP, mg/dL & $5.7 \%$ & $4.4 \%$ & $\begin{array}{l}\text { Immuno-nephelometry } \\
\text { (N High Sensitivity CRP, Dade Behring Inc.) }\end{array}$ \\
\hline
\end{tabular}

CRP, C-reactive protein; CV, coefficient of variations; HDL-C, high-density lipoprotein cholesterol.

A At Baseline

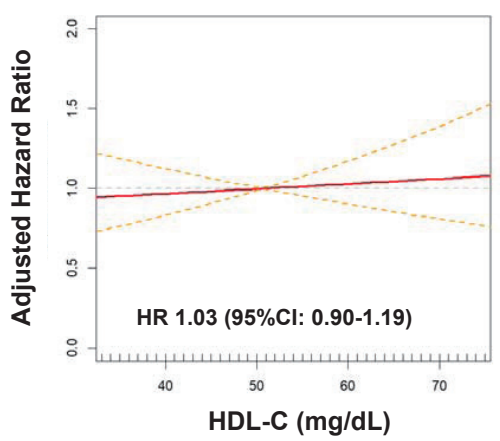

C Absolute Change

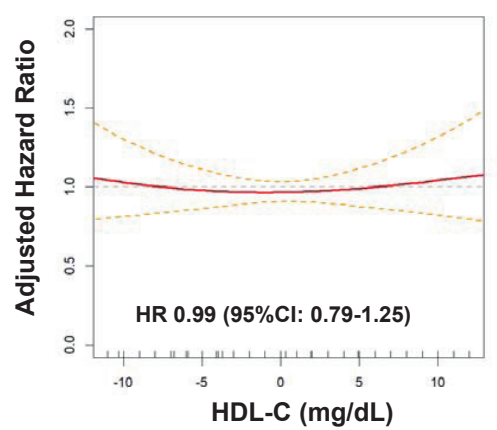

\section{B At 6 Months}

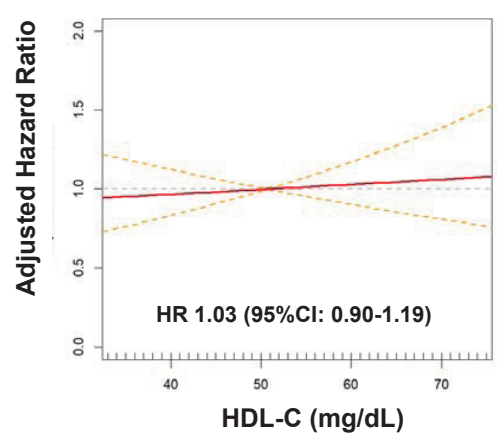

D Relative Change

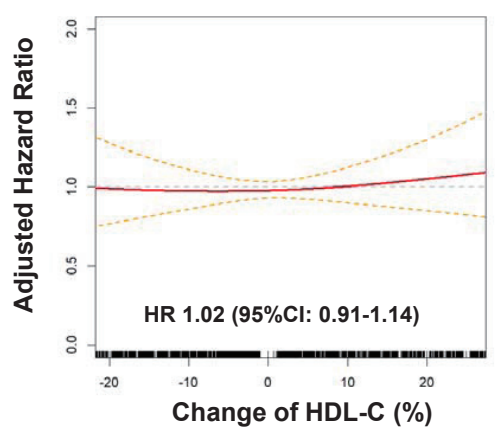

Supplementary Fig. 1. Adjusted Risks of HDL-C Values for Cardiovascular death

Red line indicates hazard ratio with penalized smoothing splines adjusted by covariates shown in Table1. Dashed yellow line indicates its 95\% confidence interval. $\mathrm{HR}=$ hazard ratio. 


\section{A At Baseline}
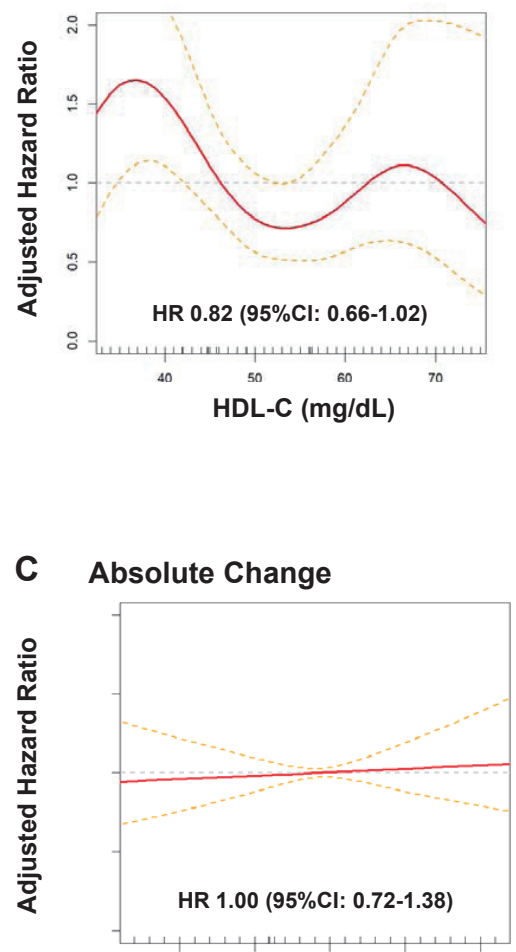

HDL-C (mg/dL)

\section{B At 6 Months}

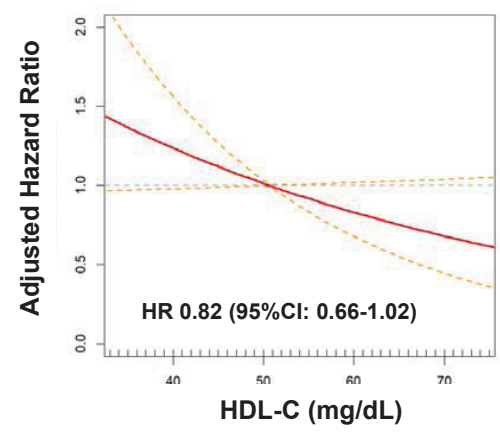

D Relative Change

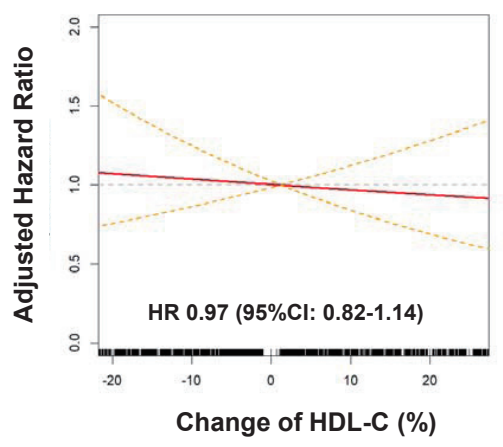

B At 6 Months

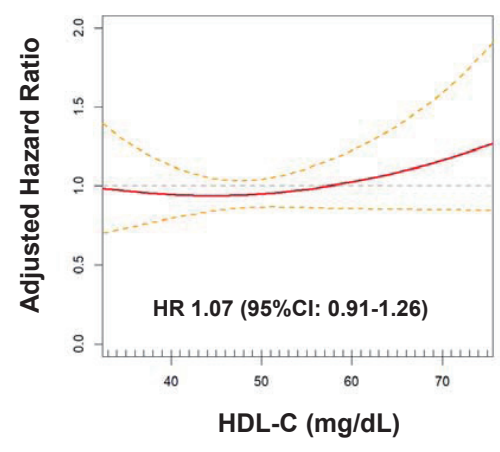

D Relative Change

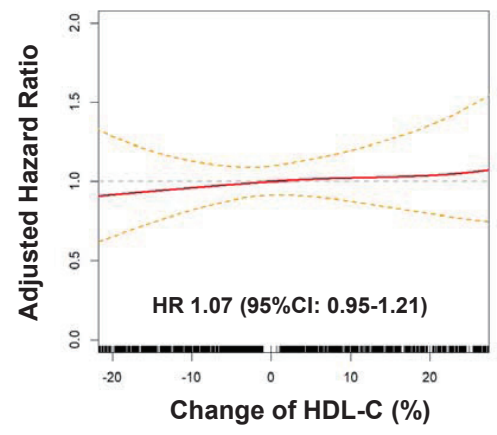

Supplementary Fig. 2. Adjusted Risks of HDL-C Values for non-fatal myocardial infraction

Red line indicates hazard ratio with penalized smoothing splines adjusted by covariates shown in Table1. Dashed yellow line indicates its 95\% confidence interval. $\mathrm{HR}=$ hazard ratio.

\section{A At Baseline}

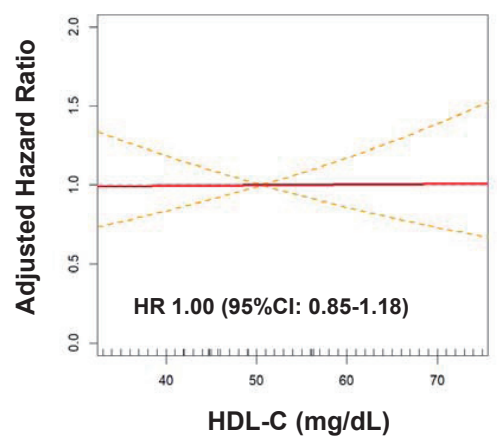

\section{Absolute Change}

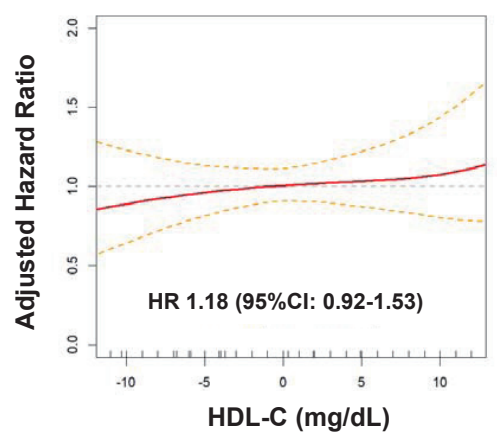

Supplementary Fig. 3. Adjusted Risks of HDL-C Values for non-fatal ischemic stroke

Red line indicates hazard ratio with penalized smoothing splines adjusted by covariates shown in Table1. Dashed yellow line indicates its 95\% confidence interval. HR= hazard ratio. 


\section{A At Baseline}

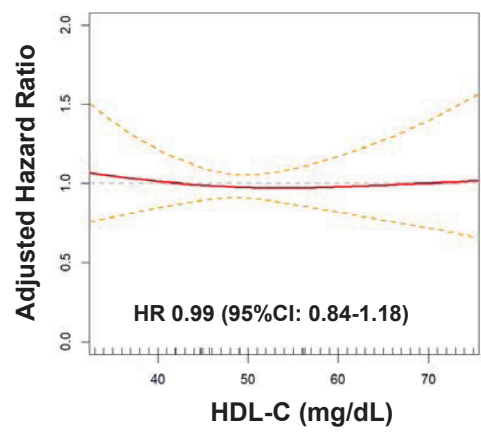

C Absolute Change

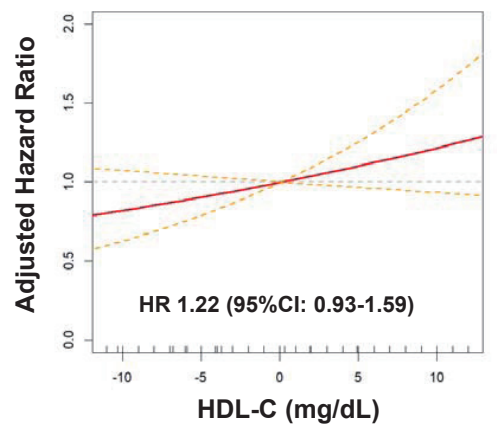

A At Baseline

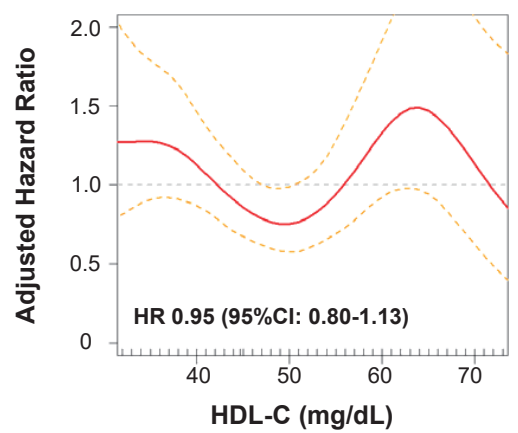

C Absolute Change

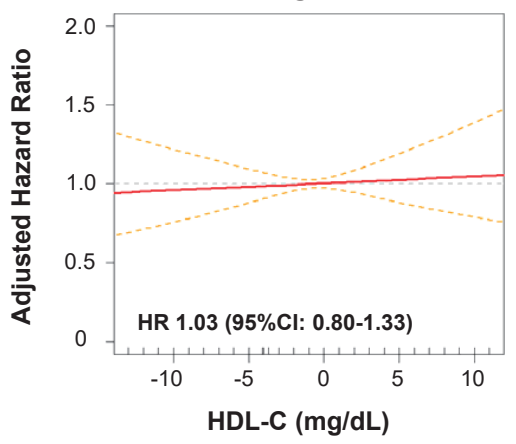

B At 6 Months

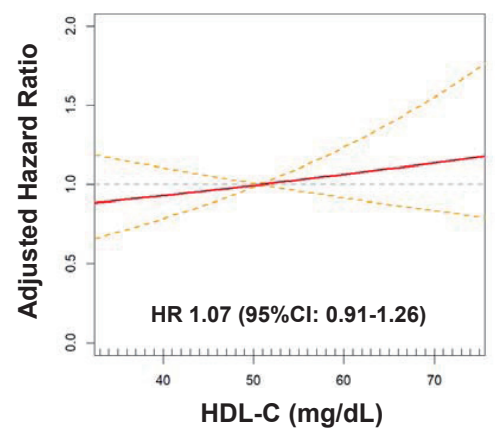

D Relative Change

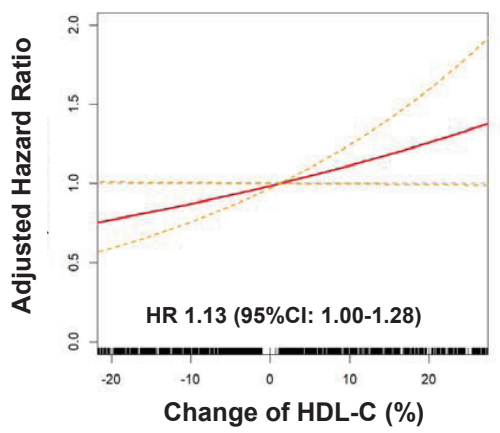

B At 6 Months

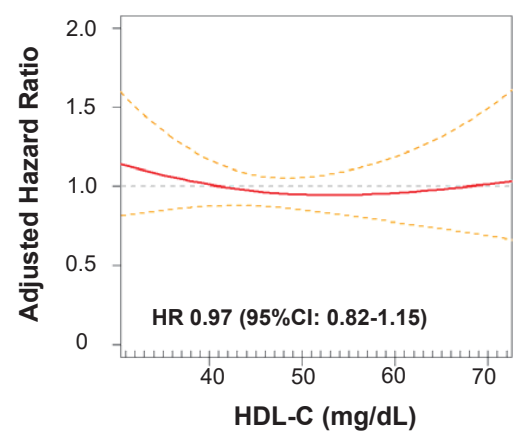

D Relative Change

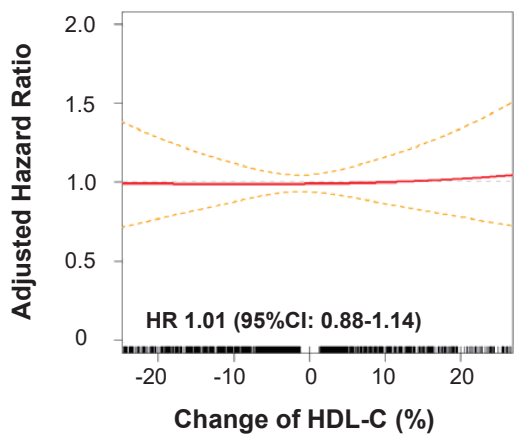

Supplementary Fig.4. Adjusted Risks of HDL-C Values for unstable angina requiring emergent admission after 6 months

Red line indicates hazard ratio with penalized smoothing splines adjusted by covariates shown in Table1. Dashed yellow line indicates its 95\% confidence interval. HR= hazard ratio.
Supplementary Fig.5. Adjusted Risks of HDL-C Values for Primary Outcome in Patients On-Treatment LDL-C $<70 \mathrm{mg} / \mathrm{dL}$ at 6 Months

Red line indicates hazard ratio with penalized smoothing splines adjusted by covariates shown in Table1. Dashed yellow line indicates its 95\% confidence interval. $\mathrm{HR}=$ hazard ratio.

Advance Publication Journal of Atherosclerosis and Thrombosis 


\section{A At Baseline}

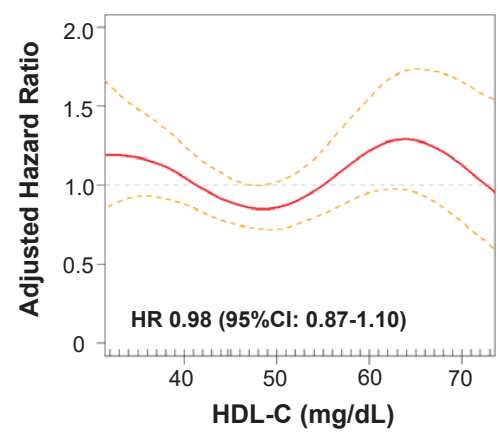

C Absolute Change

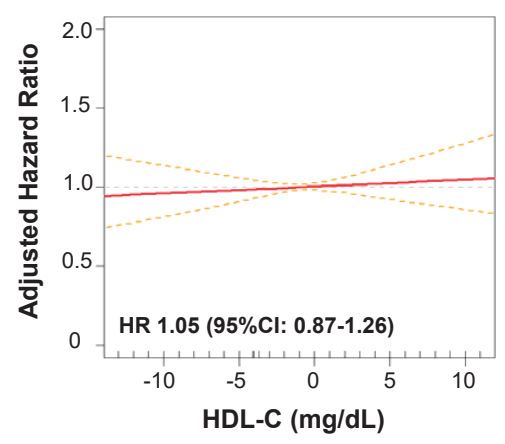

A At Baseline

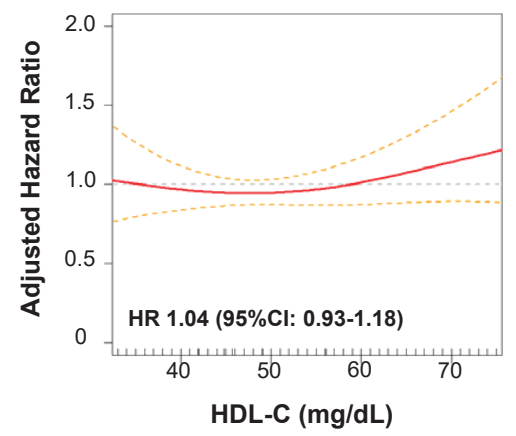

C Absolute Change

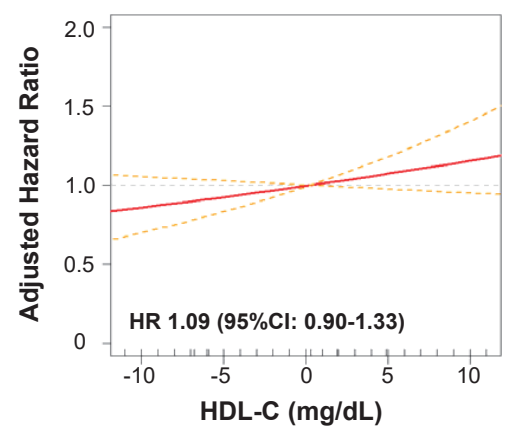

\section{B At 6 Months}

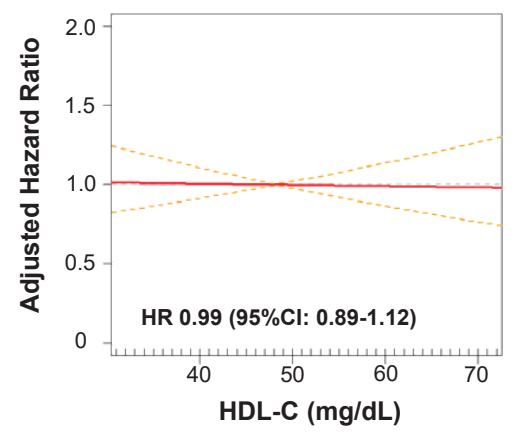

D Relative Change

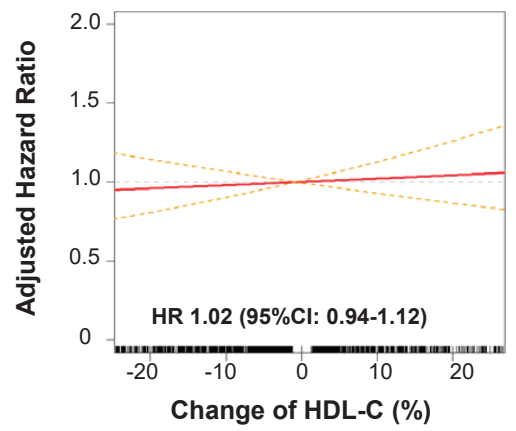

B At 6 Months

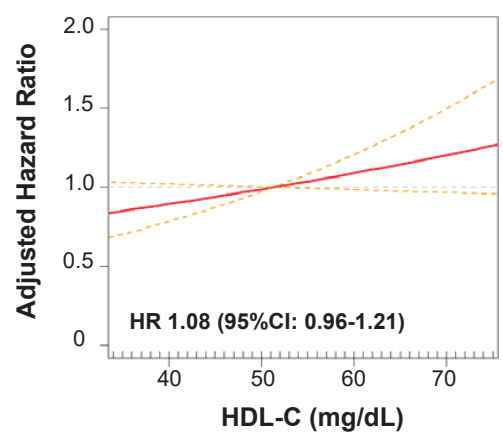

D Relative Change

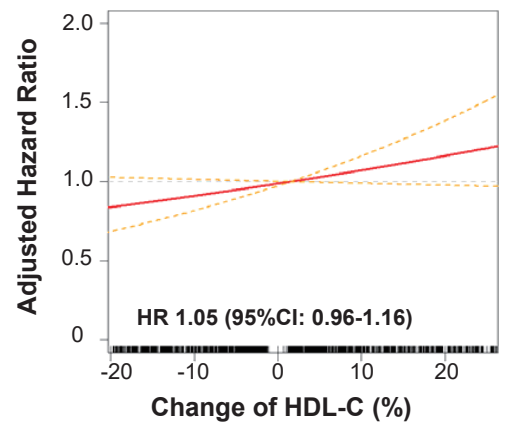

Supplementary Fig.6. Adjusted Risks of HDL-C Values for Secondary Outcome in Patients On-Treatment LDL-C $<70 \mathrm{mg} / \mathrm{dL}$ at 6 Months

Red line indicates hazard ratio with penalized smoothing splines adjusted by covariates shown in Table1. Dashed yellow line indicates its 95\% confidence interval. HR= hazard ratio.
Supplementary Fig.7. Adjusted Risks of HDL-C Values for Primary Outcome in Patients On-Treatment LDL-C 70-100 mg/ $\mathrm{dL}$ at 6 Months

Red line indicates hazard ratio with penalized smoothing splines adjusted by covariates shown in Table1. Dashed yellow line indicates its 95\% confidence interval. HR= hazard ratio. 

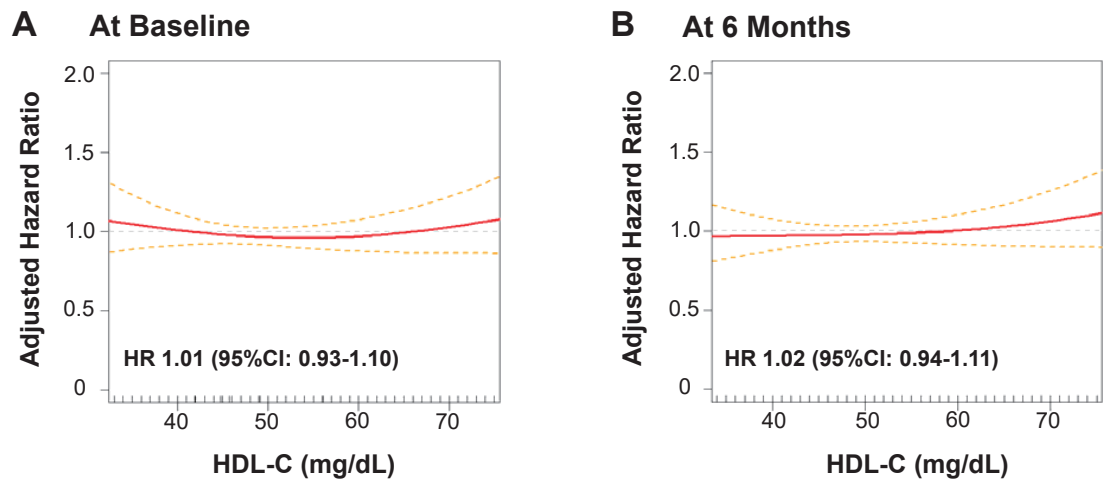
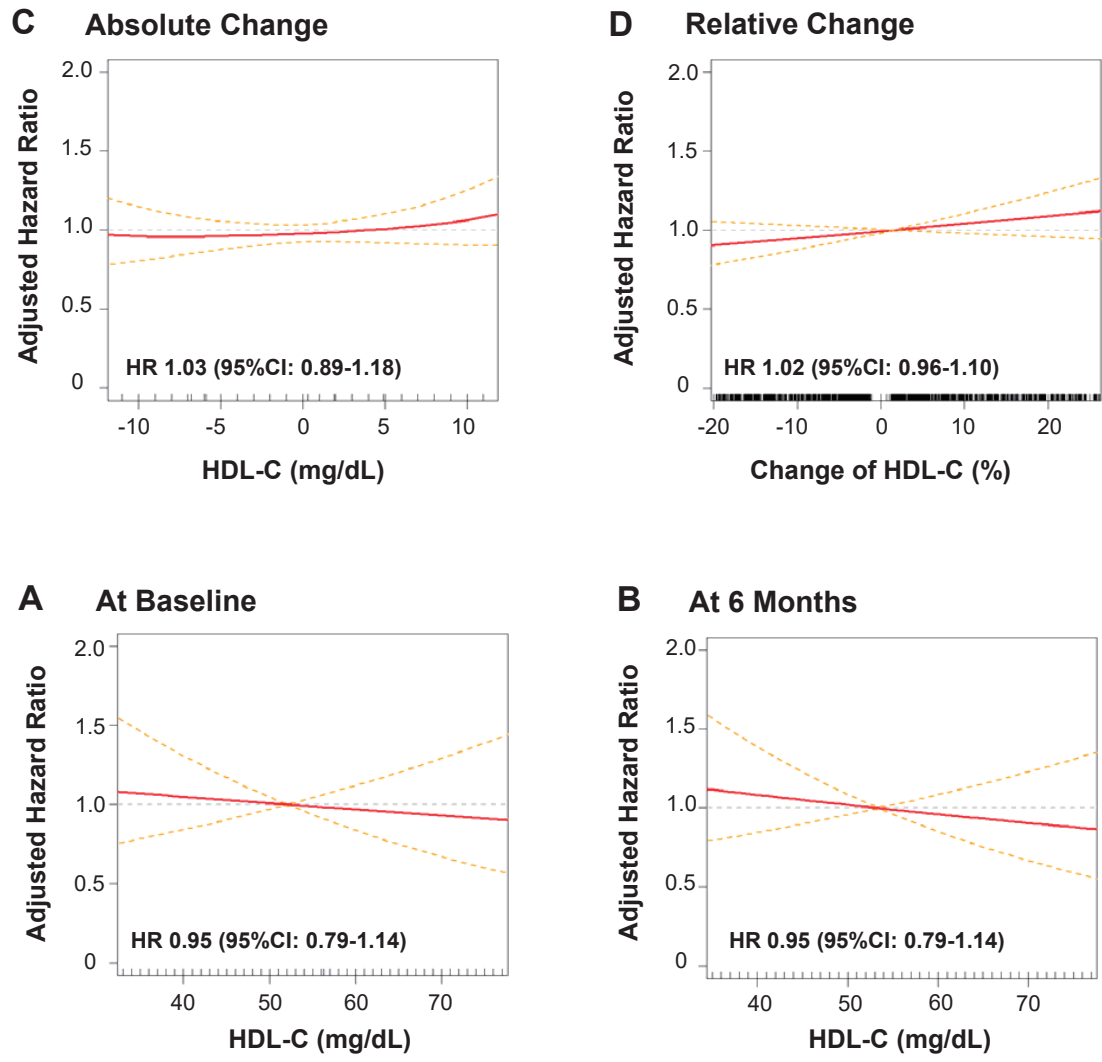

\section{Absolute Change}

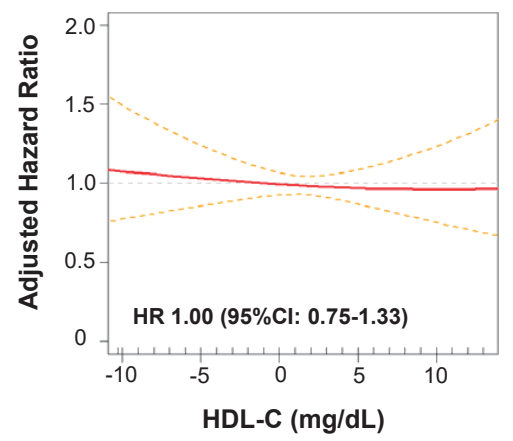

\section{Relative Change}

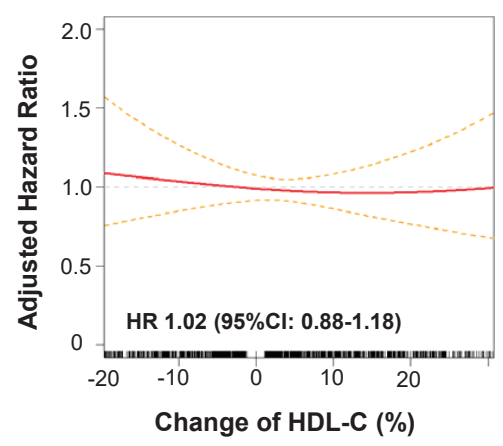

Supplementary Fig. 8. Adjusted Risks of HDL-C Values for Secondary Outcome in Patients On-Treatment LDL-C 70-100 mg/ $\mathrm{dL}$ at 6 Months

Red line indicates hazard ratio with penalized smoothing splines adjusted by covariates shown in Table1. Dashed yellow line indicates its 95\% confidence interval. $\mathrm{HR}=$ hazard ratio.
Supplementary Fig.9. Adjusted Risks of HDL-C Values for Primary Outcome in Patients On-Treatment LDL-C >100 mg/ $\mathrm{dL}$ at 6 Months

Red line indicates hazard ratio with penalized smoothing splines adjusted by covariates shown in Table1. Dashed yellow line indicates its 95\% confidence interval. HR= hazard ratio.

Advance Publication Journal of Atherosclerosis and Thrombosis 


\section{A At baseline}

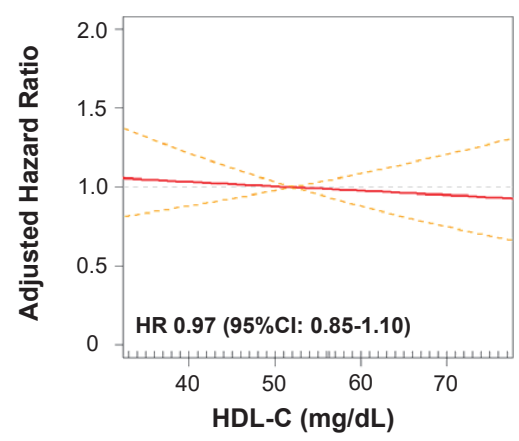

C Absolute change

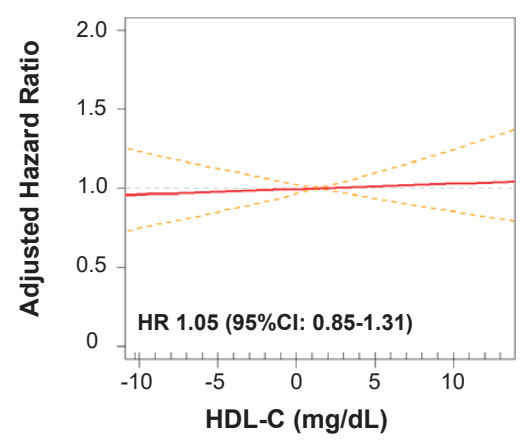

A At baseline

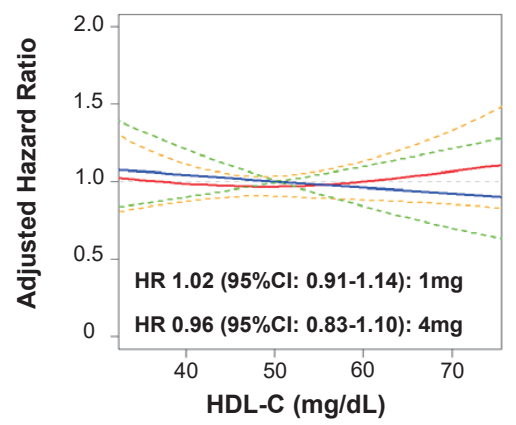

C Absolute change

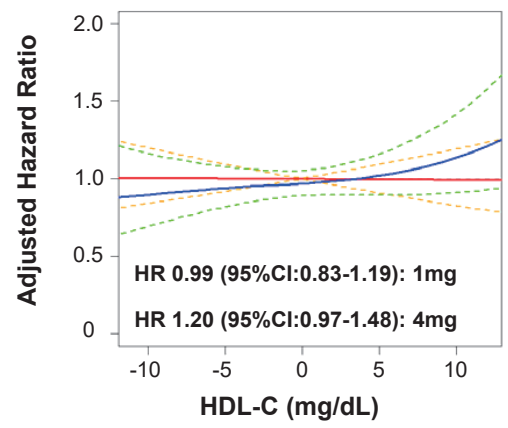

\section{B At 6 months}

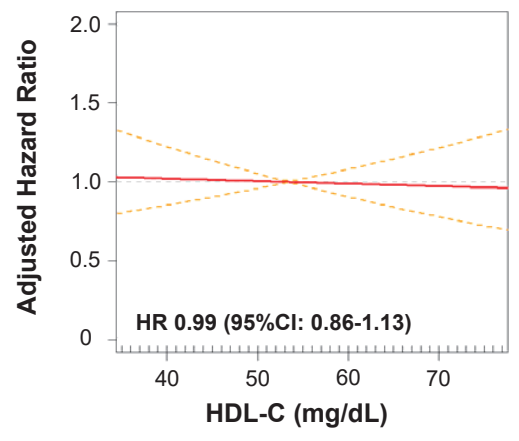

\section{Relative change}

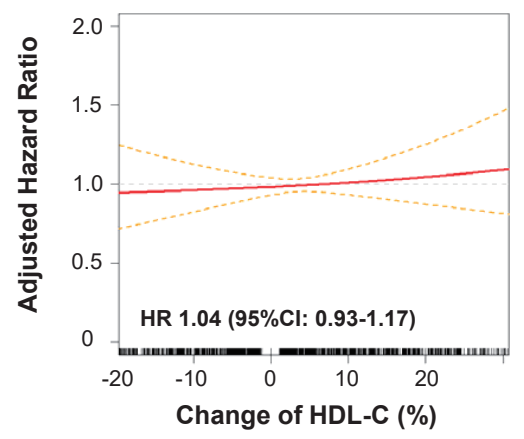

B At 6 months

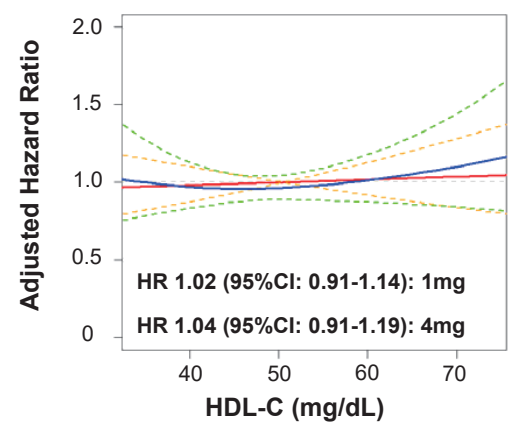

D Relative change

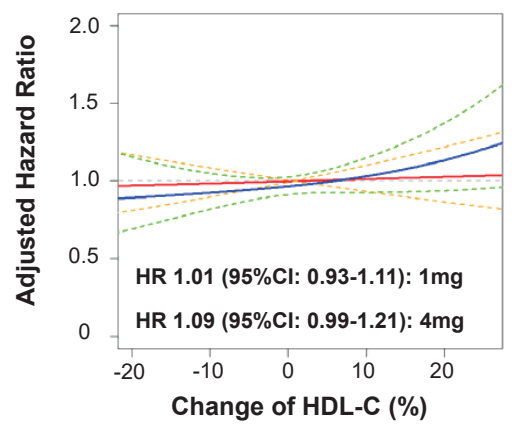

Supplementary Fig. 10. Adjusted Risks of HDL-C Values for Secondary Outcome in Patients On-Treatment LDL-C >100 mg/ $\mathrm{dL}$ at 6 Months

Red line indicates hazard ratio with penalized smoothing splines adjusted by covariates shown in Table1. Dashed yellow line indicates its 95\% confidence interval. $\mathrm{HR}=$ hazard ratio.

\section{Advance Publication Journal of Atherosclerosis and Thrombosis}




\section{A At baseline}

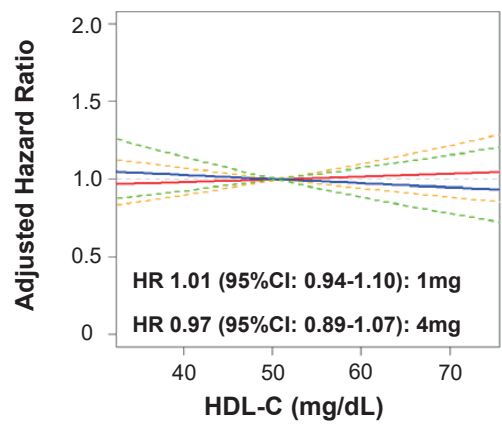

C Absolute change

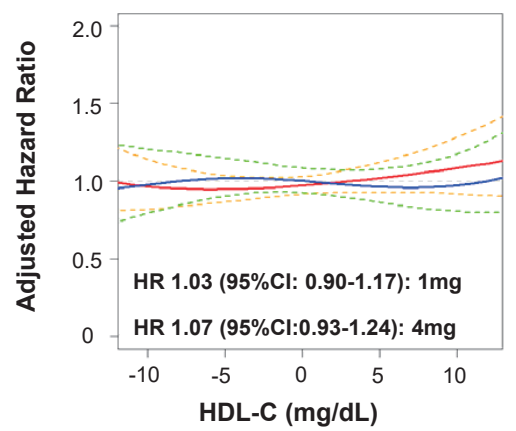

\section{B At 6 months}

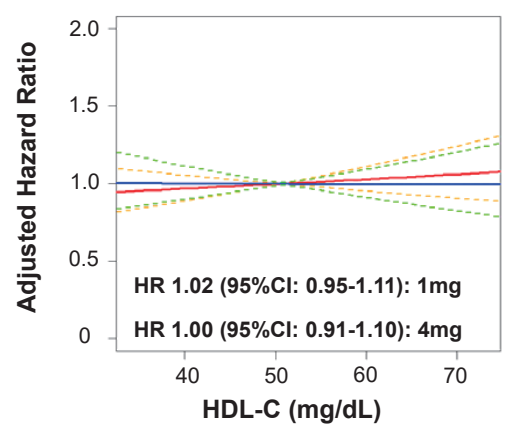

D Relative change

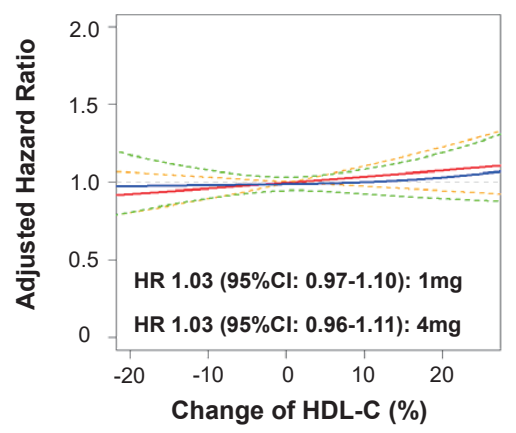

Supplementary Fig. 12. Adjusted Risks of HDL-C Levels for Secondary Outcome Both in Patients with Low Dose $(1 \mathrm{mg})$ and High Dose (4 mg) Pitavastatin

Red $(1 \mathrm{mg})$ and blue $(4 \mathrm{mg})$ lines indicate hazard ratio with penalized smoothing splines adjusted by covariates shown in Table1. Dashed yellow $(1 \mathrm{mg})$ and green $(4 \mathrm{mg})$ lines indicate those $95 \%$ confidence interval.

$\mathrm{HR}=$ hazard ratio. 